\title{
Diel quenching of Southern Ocean phytoplankton fluorescence is related to iron limitation
}

\author{
Christina Schallenberg ${ }^{1}$, Robert F. Strzepek ${ }^{1}$, Nina Schuback ${ }^{2}$, Lesley A. Clementson ${ }^{3}$, Philip W. Boyd ${ }^{1,4}$, and \\ Thomas W. Trull ${ }^{1,3}$ \\ ${ }^{1}$ Antarctic Climate and Ecosystems Cooperative Research Centre, University of Tasmania, Hobart, Tasmania, Australia \\ ${ }^{2}$ Swiss Polar Institute, École Polytechnique Fédérale de Lausanne, Lausanne, Switzerland \\ ${ }^{3}$ Commonwealth Scientific and Industrial Research Organisation Oceans and Atmosphere Unit, Hobart, Tasmania, Australia \\ ${ }^{4}$ Institute for Marine and Antarctic Studies, University of Tasmania, Hobart, Tasmania, Australia
}

Correspondence: Christina Schallenberg (christina.schallenberg@utas.edu.au)

Received: 26 August 2019 - Discussion started: 4 September 2019

Revised: 10 December 2019 - Accepted: 3 January 2020 - Published: 17 February 2020

\begin{abstract}
Evaluation of photosynthetic competency in time and space is critical for better estimates and models of oceanic primary productivity. This is especially true for areas where the lack of iron ( $\mathrm{Fe})$ limits phytoplankton productivity, such as the Southern Ocean. Assessment of photosynthetic competency on large scales remains challenging, but phytoplankton chlorophyll $a$ fluorescence $(\mathrm{ChlF})$ is a signal that holds promise in this respect as it is affected by, and consequently provides information about, the photosynthetic efficiency of the organism. A second process affecting the ChlF signal is heat dissipation of absorbed light energy, referred to as non-photochemical quenching (NPQ). NPQ is triggered when excess energy is absorbed, i.e. when more light is absorbed than can be used directly for photosynthetic carbon fixation. The effect of NPQ on the ChlF signal complicates its interpretation in terms of photosynthetic efficiency, and therefore most approaches relating ChlF parameters to photosynthetic efficiency seek to minimize the influence of NPQ by working under conditions of sub-saturating irradiance. Here, we propose that NPQ itself holds potential as an easily acquired optical signal indicative of phytoplankton physiological state with respect to Fe limitation.

We present data from a research voyage to the Subantarctic Zone south of Australia. Incubation experiments confirmed that resident phytoplankton were Fe-limited, as the maximum quantum yield of primary photochemistry, $F_{\mathrm{v}} / F_{\mathrm{m}}$, measured with a fast repetition rate fluorometer (FRRf), increased significantly with Fe addition. The NPQ "capacity" of the phytoplankton also showed sensitivity to Fe addition,
\end{abstract}

decreasing with increased Fe availability, confirming previous work. The fortuitous presence of a remnant warm-core eddy in the vicinity of the study area allowed comparison of fluorescence behaviour between two distinct water masses, with the colder water showing significantly lower $F_{\mathrm{v}} / F_{\mathrm{m}}$ than the warmer eddy waters, suggesting a difference in $\mathrm{Fe}$ limitation status between the two water masses. Again, NPQ capacity measured with the FRRf mirrored the behaviour observed in $F_{\mathrm{v}} / F_{\mathrm{m}}$, decreasing as $F_{\mathrm{v}} / F_{\mathrm{m}}$ increased in the warmer water mass. We also analysed the diel quenching of underway fluorescence measured with a standard fluorometer, such as is frequently used to monitor ambient chlorophyll $a$ concentrations, and found a significant difference in behaviour between the two water masses. This difference was quantified by defining an NPQ parameter akin to the Stern-Volmer parameterization of NPQ, exploiting the fluorescence quenching induced by diel fluctuations in incident irradiance. We propose that monitoring of this novel NPQ parameter may enable assessment of phytoplankton physiological status (related to Fe availability) based on measurements made with standard fluorometers, as ubiquitously used on moorings, ships, floats and gliders.

\section{Introduction}

A key limitation to confidence in estimates of global ocean productivity is the lack of readily obtained information regarding the physiological status of phytoplankton. Assess- 
ment of photosynthetic competency in time and space is a crucial requirement for improved estimates and models of oceanic primary productivity. This is especially true for areas where iron $(\mathrm{Fe})$ limitation is prevalent, such as the Southern Ocean (Boyd et al., 2007; Moore et al., 2013). Fe-induced variations in primary productivity in this region have been shown to arise from physiological drivers of photosynthesis that are currently poorly represented in models of productivity (Hiscock et al., 2008). The Southern Ocean is of particular interest because of its large influence on the global carbon cycle, which is directly linked to photosynthetic performance of the resident phytoplankton (Martínez-García et al., 2014; Sigman and Boyle, 2000). While photosynthetic performance can readily be measured on small scales, i.e. during ship-based surveys conducting incubations for estimates of primary productivity, assessment of photosynthetic competency on larger scales remains challenging. Fluorescence emitted by phytoplankton upon absorption of light is a signal that holds great promise in this respect, as it stems directly from the photosynthetic apparatus of phytoplankton and can be measured by instruments mounted on drifters, floats, gliders and even satellites (Letelier et al., 1997; Behrenfeld et al., 2009; Huot et al., 2013; Morrison, 2003; Schallenberg et al., 2008). Indeed, the signal has been shown to hold the potential for providing information on the physiological state of phytoplankton (Letelier et al., 1997; Behrenfeld et al., 2009; Morrison and Goodwin, 2010; Schallenberg et al., 2008).

Chlorophyll $a$ fluorescence (ChlF) is one of three pathways that light energy can take once absorbed by the lightharvesting antenna of photosystem II (PSII) of a photosynthetic organism. The other two possible pathways are photochemistry (i.e. primary charge separation in reaction centre II, RCII) and heat dissipation. Heat dissipation of absorbed light energy can be upregulated in situations where light energy is absorbed in excess of photosynthetic capacity, which has the potential to damage the photosynthetic apparatus. As the three possible pathways of absorbed energy are complementary, an upregulation of heat dissipation will quench the ChlF signal, which is known as non-photochemical quenching (NPQ) (Horton et al., 1996; Krause and Weis, 1984; Müller et al., 2001).

At midday, NPQ can depress the ChlF signal by up to $90 \%$ (Falkowski et al., 2017). This affects daytime ChlF data from ships, satellites, bio-optical floats and gliders, the latest and rapidly growing additions to the oceanographic toolbox (Biermann et al., 2015; Grenier et al., 2015; Xing et al., 2012, 2018). Sensitivity of NPQ to the light acclimation state of phytoplankton has been demonstrated (Milligan et al., 2012; O'Malley et al., 2014), and other drivers of NPQ, including nutrient status and species composition, have also been suggested (e.g. Kropuenske et al., 2009; Schallenberg et al., 2008; Schuback et al., 2015). An empirical relationship between sea surface temperature and NPQ in the Southern Ocean has been described (Browning et al., 2014), but the underlying controls are not fully understood.
Active fluorometers such as a fast repetition rate fluorometer (FRRf) exploit the complementary nature of the three possible pathways of absorbed light energy. Triggering and detecting changes in ChlF in the dark-regulated state (i.e. when NPQ is relaxed and does not quench $\mathrm{ChlF}$ ), allows derivation of the commonly used parameter $F_{\mathrm{v}} / F_{\mathrm{m}} . F_{\mathrm{v}} / F_{\mathrm{m}}$, often referred to as the maximum quantum yield of PSII, is a measure of the maximum fraction of absorbed light energy that can be used for primary charge separation in RCII. Strong links have been established between phytoplankton Fe status and $F_{\mathrm{v}} / F_{\mathrm{m}}$. As Fe becomes more and more limiting, $F_{\mathrm{v}} / F_{\mathrm{m}}$ decreases (Geider et al., 1993; Greene et al., 1992). Furthermore, benchtop FRRf instruments can quantify the induction of NPQ in response to increases in absorbed light energy, and recent studies have found a strong link between the capacity to induce NPQ and the Fe limitation status of phytoplankton (Alderkamp et al., 2012; Schuback et al., 2015; Schuback and Tortell, 2019).

The term "non-photochemical quenching" is a blanket term for a number of processes and parameterizations, with whole books dedicated to its many manifestations (e.g. Demmig-Adams et al., 2014). At its core, it is a photoprotective mechanism that safely removes excess excitation energy from the light-harvesting system of photosynthesizers (Müller et al., 2001). It can be assessed in many ways, the most clearly defined ones are measured with active fluorometers such as FRRf, which allows for measurements in both the dark- and light-regulated state. Common parameterizations of NPQ include the Stern-Volmer (SV) and normalized Stern-Volmer (NSV) parameterizations, but a myriad of other definitions are in use (e.g. Rohacek, 2002). In a less strictly defined manner, NPQ can also be detected in measurements that are made with what we will call "standard fluorometers" (SF) in this paper, i.e. fluorometers conventionally employed on floats, gliders, moorings and ships, to estimate ambient chlorophyll $a$ concentrations as a proxy for phytoplankton biomass (e.g. Roesler et al., 2017). Here, NPQ can take the form of depressed fluorescence in the middle of the day relative to the night, or it can manifest as a depression of fluorescence towards the ocean surface in daytime fluorescence profiles (Biermann et al., 2015; Grenier et al., 2015; Xing et al., 2012, 2018). Standard fluorometers are deployed ubiquitously in the oceans and can be operated remotely; the prospect of harnessing physiological information contained in the NPQ signal they detect is thus tantalizing. Given the link between NPQ - as estimated with active fluorometers and the Fe limitation status of phytoplankton (Alderkamp et al., 2012; Schuback et al., 2015; Schuback and Tortell, 2019), we investigated whether the NPQ signal detected by a standard fluorometer can also be interpreted with respect to the Fe limitation status of the resident phytoplankton community.

The two main objectives of this study are as follows: (i) link NPQ capacity as measured with a FRRf to NPQ measured with a standard fluorometer and (ii) link the NPQ sig- 


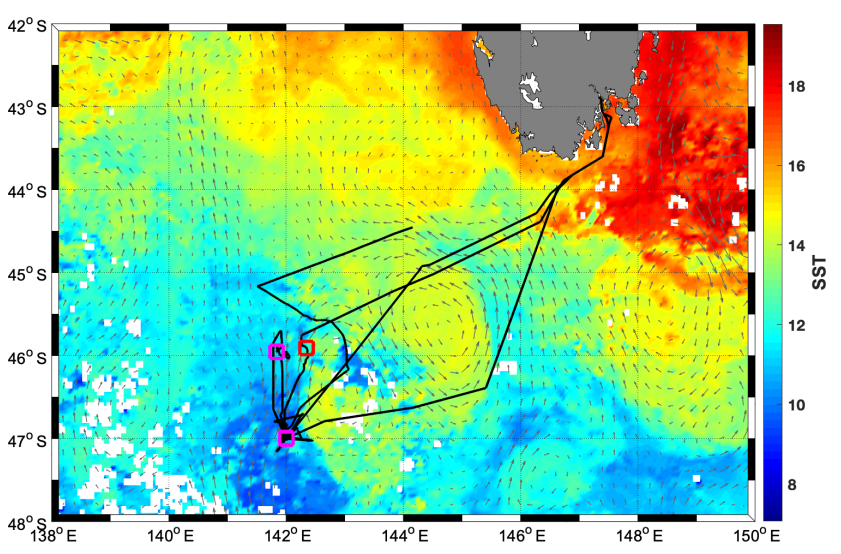

Figure 1. Average sea surface temperature (SST) for March 2018 from the MODIS-Aqua satellite, overlaid with geostrophic currents for 16 March 2018 (grey arrows) and the cruise track (black line), as well as CTD locations in the cold water mass (purple squares) and in the warm water mass (red square).

nals from both to the Fe limitation status of the resident phytoplankton community. The first objective accounts for the fact that measurements with an FRRf are made under very controlled conditions, while the fluorescence detected with a standard fluorometer is measured under ambient conditions that can be highly variable due to differences in incident sunlight, in the rate of change in illumination (e.g. due to passing clouds) and in the mixing depth, which also affects light history and acclimation. We further note that there is a shipspecific period of "dark-acclimation" prior to measurement if the standard fluorometer is installed on a ship's underway seawater line, yielding an acclimation status of the phytoplankton that is neither fully dark-regulated nor fully lightregulated, since some NPQ components can be reversed on the order of minutes and even seconds (Müller et al., 2001).

In order to investigate our research objectives, we undertook the following measurements and experiments on a voyage to the Subantarctic Zone (SAZ) south of Australia: (1) deck-board incubation experiments under controlled $\mathrm{Fe}$ conditions to confirm the link between Fe limitation and NPQ capacity, as measured with an FRRf, in the resident phytoplankton. (2) FRRf measurements on samples from the underway seawater line, yielding estimates of $F_{\mathrm{v}} / F_{\mathrm{m}}$ and NPQ capacity that could be related to the Fe limitation status of the phytoplankton. This step revealed that two distinct water masses had been repeatedly sampled by the ship, with significantly different $F_{\mathrm{v}} / F_{\mathrm{m}}$, indicating differences in their Fe limitation status. (3) NPQ estimated from the standard fluorometer on the underway seawater line was linked to the different water masses and thus to Fe limitation status, as well as to $F_{\mathrm{v}} / F_{\mathrm{m}}$ and NPQ capacity measured with an FRRf.

\section{Methods}

\subsection{Oceanographic setting and sampling}

A research voyage to the Southern Ocean Time Series (SOTS) mooring site near $140^{\circ} \mathrm{E}$ and $47^{\circ} \mathrm{S}$ took place from 3 to 20 March 2018 aboard the RV Investigator. The SOTS site lies in the SAZ southwest of Tasmania, an area of considerable mesoscale and sub-mesoscale variability (Shadwick et al., 2015; Weeding and Trull, 2014). During occupation of the area, a remnant eddy with sea surface temperatures (SST) $>14{ }^{\circ} \mathrm{C}$ was just east of the SOTS site and was visited multiple times by the ship (Fig. 1).

The ship's underway seawater supply, which had an intake in the ship's drop keel (water depth $\sim 7 \mathrm{~m}$ ), was equipped with a WETStar fluorometer (Wetlabs, Inc., Philomath, Oregon, USA) that measured $\mathrm{ChlF}$ at $695 \mathrm{~nm}$ (excitation at $460 \mathrm{~nm}$ ) continuously throughout the voyage. Travel time through the ship's plumbing from intake to the fluorometer was between 1 and $2 \mathrm{~min}$. The underway seawater line also supplied water to a WETLabs absorption and attenuation metre (ac-9) in flow-through mode (see below). At regular intervals, the underway seawater supply was sampled for pigment analysis by high-performance liquid chromatography (HPLC), particulate absorption spectra following the filter pad approach (Mitchell, 1990), chlorophyll $a$ concentration analysed fluorometrically (Chl $a$ ) and for fluorescence light curves measured with an FRRf (more details on the respective methods below). Oceanic profiles (conductivity, temperature, depth, hereafter CTD) were collected at 6 stations using Sea-Bird SBE 9plus instrumentation, with associated sampling conducted from a 36-bottle rosette equipped with $12 \mathrm{~L}$ Niskin bottles. Onboard measurements of oxygen and salinity on discrete samples from the Niskin bottles were used to calibrate CTD sensors. Samples for macronutrients $\left(\mathrm{NO}_{x}\right.$ (sum of nitrate and nitrite), silicate, phosphate) were also drawn from Niskin bottles and analysed onboard with a Seal AA3 segmented flow instrument following the methods of Rees et al. (2019).

\subsection{Incubation experiments}

At three stations, all located in close vicinity to $47^{\circ} \mathrm{S}, 142^{\circ} \mathrm{E}$, either a trace-metal-clean rosette system (TMR) or a tracemetal-clean pumped "fish" (i.e. a submerged body towed abeam of the ship and outside the ship wake with an intake at 3-5 $\mathrm{m}$ depth) were deployed in order to retrieve samples uncontaminated by trace metals. For each of the three incubation experiments, one initial HPLC sample was drawn and four acid-washed polycarbonate bottles $(250 \mathrm{~mL}$ each) were filled with unfiltered seawater from the mixed-layer and incubated in a deck incubator that was continuously supplied with surface seawater for temperature control. Light levels were controlled with mesh bags placed around the bottles 
Table 1. Details of incubation experiments.

\begin{tabular}{llrllrrrr}
\hline $\begin{array}{l}\text { Experiment } \\
\text { no. }\end{array}$ & $\begin{array}{l}\text { Date } \\
\text { (UTC) }\end{array}$ & $\begin{array}{r}\text { Sampling time } \\
\text { (UTC) }\end{array}$ & $\begin{array}{l}\text { Sampling } \\
\text { method }\end{array}$ & $\begin{array}{l}\text { SST } \\
\left({ }^{\circ} \mathrm{C}\right)\end{array}$ & $\begin{array}{r}\text { Light level } \\
(\% \text { of surface })\end{array}$ & $\begin{array}{r}\text { Duration } \\
(\mathrm{h})\end{array}$ & $\begin{array}{r}\text { Starting Chl } a \\
\text { concentration } \\
\left(\mathrm{mg} \mathrm{m}^{-3}\right)\end{array}$ & $\begin{array}{r}\text { Initial } \\
F_{\mathrm{V}} / F_{\mathrm{m}}\end{array}$ \\
\hline 1 & 6 Mar 2018 & $20: 30$ & TMR $(35 \mathrm{~m})$ & 10.7 & 67 & 53 & 0.35 \\
2 & 8 Mar 2018 & $18: 40$ & Fish & 11.2 & 67 & 55 & 0.33 \\
3 & 13 Mar 2018 & $22: 30$ & Fish & 10.5 & 25 & 51.5 & 0.30 \\
\hline
\end{tabular}

(see Table 1). Each experiment consisted of the following four treatments (final concentrations indicated):

- $20 \mathrm{nM}$ desferrioxamine B (DFB), a strong iron chelator,

- control (no additions)

- $0.2 \mathrm{nM} \mathrm{Fe}$ (added as $\mathrm{FeCl}_{3}$ dissolved in acidified Milli$\mathrm{Q}$ water),

- $2 \mathrm{nM} \mathrm{Fe}$ (added as $\mathrm{FeCl}_{3}$ dissolved in acidified Milli-Q water).

Incubations were run for $\sim 51.5-55 \mathrm{~h}$ (see Table 1 ), and at the end of the experiments each polycarbonate bottle was sub-sampled for an FRRf measurement (see below). Fluorescence parameters are sensitive to the light history experienced by the phytoplankton, so the time of day at which measurements are made can change results. In order to make all four treatments comparable to each other, they had to be measured as closely in time as possible, hence only one replicate per treatment was prepared, allowing us to complete one round of FRRf measurements in less than $2 \mathrm{~h}$. The duration of the incubations was chosen to allow an adequate physiological response time (see Fig. S1 in the Supplement for the time course of experiment 1 , indicating that results were consistent between 29 and $52 \mathrm{~h}$ sampling points but more pronounced after $52 \mathrm{~h}$ ).

\subsection{Photosynthetic competency: FRRf measurements}

Photosystem II (PSII) variable ChlF was measured on a fast repetition rate fluorometer (FRRf, Chelsea Technologies Group FastOcean Sensor fitted with an Act2 laboratory system) using the factory-supplied Act2Run software. All measurements were made in a temperature-controlled room that was kept at the ambient SST temperature $\left(10-14^{\circ} \mathrm{C}\right)$. Prior to each measurement, a blank was prepared by filtering a small aliquot of sample through a $0.2 \mu \mathrm{m}$ syringe filter and was subsequently subtracted from all measured fluorescence signals. The excitation wavelength of the FRRf's light-emitting diodes (LEDs) was $450 \mathrm{~nm}$, and the instrument was used in single turnover mode, with a saturation phase comprised of 100 flashlets on a $2 \mu$ s pitch and a relaxation phase comprised of 40 flashlets on a $60 \mu \mathrm{s}$ pitch. Samples were low-light acclimated (at 2-5 $\mu$ mol quanta $\mathrm{m}^{-2} \mathrm{~s}^{-1}$ ) for $\sim 1 \mathrm{~h}$ prior to each fluorescence light curve measurement to ensure relaxation of fast-relaxing NPQ as well as some (but likely not all) slow-relaxing NPQ. Measurement of each fluorescence light curve took $24 \mathrm{~min}$ and was comprised of eight light steps of increasing intensity (see Fig. S2 for details). Fluorescence light curves were optimized to yield estimates of NPQ capacity at light intensities of either $750 \mu$ mol quanta $\mathrm{m}^{-2} \mathrm{~s}^{-1}$ (for samples from the underway seawater system) or $1000 \mu$ mol quanta $\mathrm{m}^{-2} \mathrm{~s}^{-1}$ (incubation samples). These high light intensities were chosen based on experimentation earlier in the voyage and represent a balance such that a curve could still be fitted to the fluorescence induction data, while maximizing the NPQ signal. Since maximum NPQ capacity was our main focus, we chose an experimental design that struck a balance between (i) ensuring a good fit at the maximum light intensity, (ii) increasing light levels slowly enough to allow the cells to reach steady-state quenching (thus choosing longer time steps at the more stressful high light intensities), and (iii) keeping the fluorescence light curves as short as possible so that the four treatments in each incubation experiment could be measured within the smallest time frame possible $(<2 \mathrm{~h})$ in recognition of the sensitivity of fluorescence parameters to light history and time of day.

Three measured fluorescence signals, $F_{\mathrm{o}}, F_{\mathrm{m}}$ and $F_{\mathrm{m}}^{\prime}$ were used to calculate fluorescence parameters, following Rohacek (2002). $F_{\mathrm{o}}$ and $F_{\mathrm{m}}$ refer to minimum and maximum fluorescence in the dark-acclimated state, while $F_{\mathrm{m}}^{\prime}$ is the maximum fluorescence in the light-regulated state, in this case measured at the highest light level of the respective fluorescence light curve.

The maximum quantum yield of PSII, $F_{\mathrm{v}} / F_{\mathrm{m}}$, was estimated from fluorescence measurements during the dark step of the fluorescence light curve as follows:

$\frac{F_{\mathrm{v}}}{F_{\mathrm{m}}}=\frac{F_{\mathrm{m}}-F_{\mathrm{o}}}{F_{\mathrm{m}}}$.

There are a number of different NPQ formulations available in the literature (e.g. see Rohacek, 2002), each with their respective advantages and disadvantages. We chose to focus on two parameterizations, i.e. Stern-Volmer $\left(\mathrm{NPQ}_{\mathrm{SV}}\right)$ and the normalized Stern-Volmer NPQ $\left(\mathrm{NPQ}_{N S V}\right)$ :

$\mathrm{NPQ}_{\mathrm{SV}}=\frac{F_{\mathrm{m}}-F_{\mathrm{m}}^{\prime}}{F_{\mathrm{m}}^{\prime}}$, 
$\mathrm{NPQ}_{\mathrm{NSV}}=\frac{F_{\mathrm{o}}^{\prime}}{F_{\mathrm{v}}^{\prime}}$,

with $F_{\mathrm{o}}^{\prime}$ calculated following Oxborough and Baker (1997):

$F_{\mathrm{o}}^{\prime}=\frac{F_{\mathrm{o}}}{\left(\frac{F_{\mathrm{v}}}{F_{\mathrm{m}}}+\frac{F_{\mathrm{o}}}{F_{\mathrm{m}}^{\prime}}\right)}$,

and

$F_{\mathrm{v}}^{\prime}=F_{\mathrm{m}}^{\prime}-F_{\mathrm{o}}^{\prime}$.

Both parameters were estimated at the respective maximum light levels of the fluorescence light curves (i.e. 750 and $1000 \mu$ mol quanta $\mathrm{m}^{-2} \mathrm{~s}^{-1}$ for underway and incubation samples, respectively) and should thus be regarded as a NPQ "capacity" that can be achieved under given nutrient availabilities and light histories of the phytoplankton assemblage (see Schuback and Tortell, 2019). The light levels at which the NPQ parameters were measured are indicated in parentheses in the respective figures; see also Table 2 for a summary of fluorescence parameters discussed in this paper.

\subsection{Phytoplankton pigments and absorption}

\subsubsection{HPLC analyses}

Sample volumes of 3-4 L were filtered through a $25 \mathrm{~mm}$ glass fibre filter (Whatman GF/F), blotted dry and stored at $-80^{\circ} \mathrm{C}$ until analysis. Samples were extracted over $15-18 \mathrm{~h}$ in an acetone solution before analysis by high-performance liquid chromatography (HPLC) using a $\mathrm{C}_{8}$ column and binary gradient system with an elevated column temperature following the method of Clementson (2013). Pigments were identified by retention time and absorption spectrum from a photodiode array (PDA) detector, and concentrations of pigments were determined from commercial and international standards (Sigma, USA; DHI, Denmark).

\subsubsection{Diagnostic pigment indices}

The results from HPLC analyses were used to derive diagnostic pigment (DP) indices following Barlow et al. (2008), which give an indication of the phytoplankton community composition in terms of three functional groups: diatoms, flagellates and prokaryotes. The DP index and resulting functional groups are defined based on seven biomarker pigments as follows:

$\mathrm{DP}=\left(\right.$ alloxanthin $($ Allo $)+19^{\prime}$-hexanoyloxyfucoxanthin $($ Hex-fuco $)+19^{\prime}$-butanoyloxyfucoxanthin (But-fuco) + fucoxanthin (Fuco) + zeaxanthin (Zea) + chlorophyll $b$ (Chlb) + peridinin (Perid)),

Diatoms $=$ Fuco/DP,

Flagellates $=($ Allo + Hex-fuco + But-fuco $+\mathrm{Chl} b) / \mathrm{DP}$, Prokaryotes $=$ Zea/DP.

\subsubsection{Fluorometric measurement of chlorophyll}

Samples for fluorometric Chl $a$ analyses (2L) were filtered onto $25 \mathrm{~mm}$ glass fibre filters (Whatman, $\mathrm{GF} / \mathrm{F}$ ) and immediately frozen at $-80^{\circ} \mathrm{C}$. Within 3 weeks of sampling, all filters were extracted with $10 \mathrm{~mL}$ of $90 \%$ acetone at $-20^{\circ} \mathrm{C}$ for $24 \mathrm{~h}$. Fluorescence was measured on a Turner Trilogy Laboratory Fluorometer and converted to $\mathrm{Chl} a$ following the acid ratio method (Holm-Hansen et al., 1965). The fluorometer had been calibrated with a spectrophotometrically measured dilution series of Chl $a$ (Jeffrey and Humphrey, 1975).

Fluorometric $\mathrm{Chl} a$ showed excellent agreement with Chl $a$ measured using the HPLC method, albeit with an offset and a slight decrease in the slope relative to the $1: 1$ line (Fig. S3). In order to bring the $\mathrm{Chl} a$ measured fluorometrically in line with the more precise HPLC measurement (e.g. Trees et al., 1985), all fluorometric Chl $a$ estimates were corrected using the slope and intercept from the regression of HPLC Chl $a$ against fluorometric Chl $a$ $\left(\mathrm{Chl}_{\mathrm{HPLC}}=\mathrm{Chl}_{\mathrm{F}} \cdot 0.879-0.052 ; r^{2}=0.97 ; n=15 ;\right.$ standard error of the estimate $=0.029 \mathrm{mg} \mathrm{m}^{-3}$ ). All Chl $a$ estimates could thus be combined for calibration of the ac- 9 absorption line height approach (see below).

\subsubsection{Phytoplankton absorption (filter pad)}

Sample volumes of 3-4 L were filtered through a $25 \mathrm{~mm}$ glass fibre filter (Whatman GF/F), and the filter was then stored flat at $-80^{\circ} \mathrm{C}$ until analysis. Optical density spectra for total particulate matter were obtained using a Cintra 404 UV/VIS dual-beam spectrophotometer equipped with an integrating sphere. Quartz glass plates were used to hold the sample and blank filters against the integrating sphere. The optical density of the total particulate matter of each sample was obtained using a blank filter as a reference (from the same batch number as the sample filters) wetted with filtered seawater $(0.2 \mu \mathrm{m})$ and scanned from 200 to $900 \mathrm{~nm}$ with a spectral resolution of $1.3 \mathrm{~nm}$. Following the scan for total particulate matter, the sample filter was returned to the original filtering units, and any pigmented material was extracted using the method of Kishino et al. (1985). Blank reference filters were treated in the same manner. The filters were rinsed with filtered seawater and then re-scanned to determine the optical density of the detrital or non-algal matter. An estimate of the optical density due to phytoplankton was obtained as the difference between the optical density of the total particulate matter and the detrital or non-algal matter. The optical density scans were converted to absorption spectra by first normalizing the scans to zero at $750 \mathrm{~nm}$ and then correcting for the path length amplification using the coefficients of Mitchell (1990). 
Table 2. List of fluorescence-related parameters derived and discussed.

\begin{tabular}{|c|c|c|c|}
\hline & Parameter & Units & Method \\
\hline$\sigma_{\text {PSII }}$ & $\begin{array}{l}\text { Functional absorption cross } \\
\text { section of PSII }\end{array}$ & $\mathrm{nm}^{2} \mathrm{RC}^{-1}$ & $\begin{array}{l}\text { FRRf single turnover protocol during dark- } \\
\text { regulated state }\end{array}$ \\
\hline$F$ & Fluorescence & Arbitrary & $\begin{array}{l}\text { Measured with a standard fluorometer with minimal } \\
\text { or no dark-acclimation period }\end{array}$ \\
\hline$F_{\min }$ & $\begin{array}{l}\text { Minimum fluorescence in } \\
\text { the day (at high light) }\end{array}$ & Arbitrary & $\begin{array}{l}\text { Measured with a standard fluorometer, with mini- } \\
\text { mal or no dark-acclimation }\end{array}$ \\
\hline$F_{\max }$ & $\begin{array}{l}\text { Maximum fluorescence in } \\
\text { the day (at low light) }\end{array}$ & Arbitrary & $\begin{array}{l}\text { Measured with an standard fluorometer, with mini- } \\
\text { mal or no dark-acclimation }\end{array}$ \\
\hline$F_{\mathrm{V}} / F_{\mathrm{m}}$ & $\begin{array}{l}\text { Maximum quantum yield } \\
\text { of PSII }\end{array}$ & No units & $\begin{array}{l}\text { FRRf single turnover protocol during dark- } \\
\text { regulated state, calculated as }\left(F_{\mathrm{m}}-F_{\mathrm{o}}\right) / F_{\mathrm{m}}\end{array}$ \\
\hline NPQ & $\begin{array}{l}\text { Non-photochemical } \\
\text { quenching }\end{array}$ & No units & $\begin{array}{l}\text { Term comprised of a number of non-photochemical } \\
\text { quenching processes that decrease fluorescence at } \\
\text { supersaturating light intensities (e.g. } F_{\mathrm{m}}^{\prime} \text { relative to } \\
\left.F_{\mathrm{m}} \text { and } F_{\min } \text { relative to } F_{\max }\right)\end{array}$ \\
\hline $\mathrm{NPQ}_{\mathrm{NSV}}(750), \mathrm{NPQ}_{\mathrm{NSV}}(1000)$ & $\begin{array}{l}\text { Normalized } \\
\text { Volmer NPQ at light } \\
\text { intensities of } 750 \text { and } \\
1000 \mu \text { mol quanta } \mathrm{m}^{-2} \mathrm{~s}^{-1}\end{array}$ & No units & $\begin{array}{l}\text { FRRf single turnover protocol during light- } \\
\text { regulated state, i.e. Eq. (3) }\end{array}$ \\
\hline $\mathrm{NPQ}_{S V}(750), \mathrm{NPQ}_{S V}(1000)$ & $\begin{array}{l}\text { Stern-Volmer NPQ at } \\
\text { light intensities of } 750 \text { and } \\
1000 \mu \text { mol quanta } \mathrm{m}^{-2} \mathrm{~s}^{-1}\end{array}$ & No units & $\begin{array}{l}\text { FRRf single turnover protocol during light- } \\
\text { regulated state, i.e. Eq. (2) }\end{array}$ \\
\hline $\mathrm{NPQ}_{\mathrm{SF}}$ & $\begin{array}{l}\text { NPQ analogous to Stern- } \\
\text { Volmer NPQ }\end{array}$ & No units & $\begin{array}{l}\text { Measured with a standard fluorometer with mini- } \\
\text { mal or no dark-acclimation, calculated as }\left(F_{\max }-\right. \\
\left.F_{\min }\right) / F_{\min }\end{array}$ \\
\hline
\end{tabular}

\subsubsection{Particulate absorption (ac-9)}

A WETLabs ac-9 instrument with $25 \mathrm{~cm}$ flow tubes was employed in underway mode on the underway seawater line of the RV Investigator. The instrument was immersed in the upright position in a flow-through water bath for temperature control, and the flow tubes were shielded from ambient light. Flow was upwards through the tubes and trickled from there into the water bath, where an overflow valve controlled the water level. About two-thirds of the instrument was immersed, with the upper part exposed to the atmosphere. Internal instrument temperature was monitored every few hours and fluctuated between 21 and $26^{\circ} \mathrm{C}$. The inflow was manually switched between unfiltered and filtered seawater $\left(0.8 / 0.2 \mu \mathrm{m}\right.$; AcroPak ${ }^{\mathrm{TM}} 1500$ capsule filter with Supor ${ }^{\circledR}$ membrane), with filtered measurements lasting $\sim 10 \mathrm{~min}$ and conducted every $\sim 2 \mathrm{~h}$. The flow rate was 1-1.5 $\mathrm{Lmin}^{-1}$ for unfiltered seawater and not lower than $0.5 \mathrm{~L} \mathrm{~min}^{-1}$ for filtered seawater. The filter was exchanged for a new one after $10 \mathrm{~d}$.

Because we were only interested in the absorption line height at $676 \mathrm{~nm}$, only the red absorption channels of the ac-9 $(\lambda=650,676$ and $715 \mathrm{~nm})$ were processed. Analysis of repeat measurements on Milli-Q water in the laboratory prior to the voyage $(2-7 \mathrm{~min}$ each, then the average taken for each measurement) indicated that the precision of these three channels ranged from 0.0023 to $0.0028 \mathrm{~m}^{-1}(2.3 \%$ $2.9 \%$ ) when expressed in terms of the standard deviation of measurements $(n=8)$. The absolute range, determined as the difference between the maximum and minimum value of the measurements, was $0.0059-0.0071 \mathrm{~m}^{-1}(5.9 \%-7.4 \%)$.

Bubbles in the flow tubes were a common problem on the voyage and were dealt with by applying a thorough cleaning routine as well as smoothing of the time series during processing (see Supplement for details). Particulate absorption was calculated by subtracting interpolated filtered measurements (i.e. dissolved absorption) from unfiltered measurements (total absorption) at each wavelength (Slade et al., 2010). The particulate absorption line height at $676 \mathrm{~nm}$ (LH(676), $\mathrm{m}^{-1}$ ) was then calculated following Roesler and Barnard (2013), subtracting a baseline based on absorption measurements at 650 and $715 \mathrm{~nm}$. This $\mathrm{LH}(676)$ was calibrated against discrete $\mathrm{Chl} a$ (Chl $a$ from fluorometric and HPLC measurements combined; see above) and also against phytoplankton absorption as determined with the filter pad method (see Supplement). 


\subsection{Simulated in situ measurements of size-fractionated primary production}

Photosynthetic production of organic matter was measured twice during the voyage (7 and 18 March 2018; both times with water from $\left.\mathrm{SST}<11.5^{\circ} \mathrm{C}\right)$ by the 14 -carbon $\left({ }^{14} \mathrm{C}\right)$ tracer method. Algal carbon fixation was measured on samples collected pre-dawn from trace-metal-clean Niskin bottles deployed on a TMR from three or four depths: 35, 50, ( $70 \mathrm{~m}$ for the 18 March incubation) and $100 \mathrm{~m}$. Sampling depths were determined from in situ irradiance depth profiles obtained during midday CTD casts on the day prior to the collection. Samples were dispensed into $300 \mathrm{~mL}$ acid-washed polycarbonate bottles and spiked with $16 \mu \mathrm{Ci}$ of sodium ${ }^{14} \mathrm{C}$-bicarbonate $\left(\mathrm{NaH}^{14} \mathrm{CO}_{3}\right.$; specific activity $1.85 \mathrm{GBq} \mathrm{mmol}^{-1}$; PerkinElmer). Following the addition of ${ }^{14} \mathrm{C}$, samples were incubated for $24 \mathrm{~h}$ in neutral density mesh bags in a deck-board incubator. The temperature of the incubator was controlled by a continuous supply of surface seawater. Six samples (five light and one dark bottle per irradiance) were incubated under natural sunlight at six light intensities (from $67 \%$ to $0.2 \%$ of incident irradiance), which were adjusted by varying the layers of neutral density mesh. Light attenuation was measured with a Biospherical Instruments QSL2101 Quantum Scalar PAR (Photosynthetically Available Radiation) Sensor. Carbon fixation based on radioisotope measurements and $24 \mathrm{~h}$ incubations are reported to approximate net primary production (Laws, 1991).

Upon completion of the $24 \mathrm{~h}$ incubation, four replicate samples were filtered in series through 0.2, 2.0 and $20 \mu \mathrm{m}$ polycarbonate filters (Poretics) separated by $200 \mu \mathrm{m}$ nylon mesh, and two samples were filtered through $0.2 \mu \mathrm{m}$ filters (a total community "light" control and a total community "dark" control). Data for the dark-corrected size-fractionated samples are reported here. Filters were rinsed with $0.2 \mu \mathrm{m}$ filtered seawater, acidified to volatilize any remaining inorganic carbon (Boyd and Harrison, 1999) and collected in $20 \mathrm{~mL}$ glass scintillation vials (Wheaton) into which $10 \mathrm{~mL}$ of liquid scintillation cocktail (UltimaGold, PerkinElmer) was added. Samples were subsequently analysed by liquid scintillation counting (PerkinElmer Tri-Carb 2910 TR). Water-columnintegrated carbon assimilation rates were calculated using the trapezoid rule with the shallowest value extended to $0 \mathrm{~m}$ and the deepest extrapolated to a value of zero at $200 \mathrm{~m}$.

\subsection{Mooring data}

We show SOTS mooring data from the Pulse-7 deployment in 2010-2011. The mooring was equipped with a number of instruments, including a downward-looking WETLabs ECO FLNTUS fluorometer with a "bio-wiper" at $30 \mathrm{~m}$ and a wiped ECO PAR sensor at the same depth. Seawater temperature was measured at 15 discrete depths with Vemco Minilog Classic sensors (except for the shallowest sensor at $30 \mathrm{~m}$, which was a Sea-Bird Electronics SBE16plusV2), and mixed-layer depth (MLD) was calculated based on a temperature difference of $0.3{ }^{\circ} \mathrm{C}$ relative to the $30 \mathrm{~m}$ measurement. Only data with a quality flag $<2$ were used, and the fluorescence sensor had been calibrated using factorysupplied dark values and scale factors (Schallenberg et al., 2019). Fluorescence-based WETLabs ECO sensors have been shown to overestimate Chl $a$ in the Southern Ocean by up to a factor of 7 compared to pigment samples, with a factor of $\sim 4$ overestimation reported for the Indian sector of the Southern Ocean (Roesler et al., 2017). We have thus divided the fluorescence output from the FLNTUS sensor by 4 when $\mathrm{Chl} a$ concentration as a proxy of phytoplankton biomass was the entity of interest, consistent with previous approaches to fluorescence data from the SAZ (e.g. Eriksen et al., 2018). However, the fluorescence data were also used to estimate NPQ over the daily cycle, and for this exercise fluorescence was neither divided by 4 nor in any other way normalized to biomass.

NPQ from the FLNTUS fluorometer was estimated analogously to the Stern-Volmer parameterization:

$\mathrm{NPQ}_{\mathrm{SF}}=\frac{F_{\max }-F_{\min }}{F_{\min }}$,

where NPQSF stands for NPQ measured with a standard fluorometer and $F_{\max }$ and $F_{\min }$ are the maximum and minimum fluorescence measurements made with said fluorometer in a day, with the following restrictions: the daily fluorescence and PAR data were first smoothed with a loess (local regression using weighted linear least squares and a seconddegree polynomial model) filter, and $\mathrm{NPQ}_{\mathrm{SF}}$ was only estimated if the minimum fluorescence was within $2 \mathrm{~h}$ of maximum PAR. The parameter $F_{\max }$ designates the maximum smoothed fluorescence between 05:00 and 12:00 LT on a given day. This was preferable to using $F_{\max }$ from night-time because it decreases the time gap between the two fluorescence measurements and thus the likelihood of $F_{\max }$ varying due to fluctuations in Chl $a$ concentrations is reduced. Furthermore, this approach corresponds to analyses carried out on the underway fluorescence data from the SOTS voyage, as discussed below. Note that NPQ incident light, in contrast to the NPQ capacity estimated with the FRRf.

\section{Results and discussion}

\subsection{Incubation experiments: sensitivity of ChlF parameters to Fe status}

The incubation experiments were designed with the goals of (1) testing whether the resident phytoplankton were $\mathrm{Fe}$ limited and (2) investigating how NPQ capacity and $F_{\mathrm{v}} / F_{\mathrm{m}}$, as derived from FRRf measurements, respond to changes in $\mathrm{Fe}$ status. All three incubations were carried out with source waters colder than $11.5^{\circ} \mathrm{C}$ (Table 1), i.e. with waters from the colder water mass as evident in Fig. 1, and 

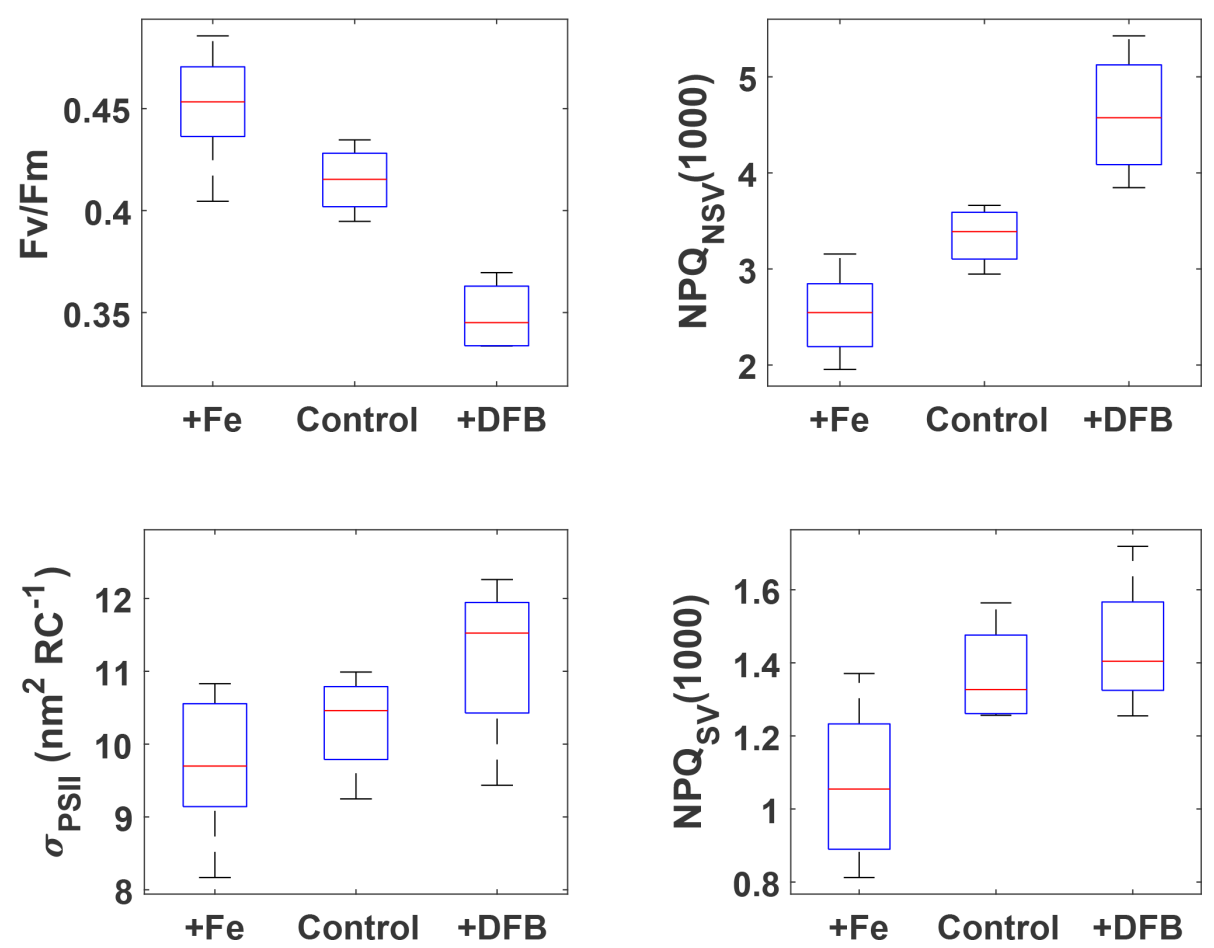

Figure 2. FRRf results after $\sim 53 \mathrm{~h}$ for the three pooled incubation experiments. The respective treatments are indicated on the $x$ axes ( 2 and $0.2 \mathrm{nM} \mathrm{Fe}$ additions were pooled into $+\mathrm{Fe}$ ), and measured parameters are on the $y$ axes. NPQ capacity was estimated at $1000 \mu \mathrm{molquanta} \mathrm{m}^{-2} \mathrm{~s}^{-1}$ after $24 \mathrm{~min}$ exposure to increasing actinic light intensities (see Fig. S2 for details of the fluorescence light curves). Box plots show the sample medians in red, with the blue boxes indicating the 25th and 75th percentiles; whiskers extend to the most extreme data points. All + Fe treatments were significantly different from the respective DFB treatments (Wilcoxon rank-sum test, $p<0.05$ ), and all + Fe treatments, except for $\sigma_{\mathrm{PSII}}$, were also significantly different from the respective control treatments.

the respective pigment compositions of the resident phytoplankton were very similar (Fig. S4), indicating a dominance of haptophytes, with some diatoms and chrysophytes also present. The pooled data from the experiments show unequivocally that $\mathrm{Fe}$ addition increased the maximum quantum yield of PSII, $F_{\mathrm{v}} / F_{\mathrm{m}}$, as has been observed previously in HNLC regions (e.g. Boyd and Abraham, 2001; Kolber et al., 1994). The NPQ capacity, measured as both NPQsv(1000) and $\mathrm{NPQ}_{\mathrm{NSV}}(1000)$, decreased with Fe addition (Fig. 2), most likely due to increased capacity for using absorbed light energy for photochemistry. The functional absorption cross section of PSII, $\sigma_{\text {PSII }}$, also decreased with Fe addition, as has been observed previously (Kolber et al., 1994; Schuback et al., 2015; Schuback and Tortell, 2019). Overall, $\sigma_{\text {PSII }}$ were very large in all treatments $\left(\sim 10-12 \mathrm{~nm}^{2} \mathrm{RC}^{-1}\right)$, as has been observed previously for low Fe-adapted Southern Ocean phytoplankton (Strzepek et al., 2012, 2019). The addition of DFB, a strong organic ligand (siderophore) that decreases Fe availability to phytoplankton, had the opposite effect to Fe addition for all parameters. The phytoplankton thus showed a clear response to changes in Fe status, which affected their ability to process absorbed light energy, evident in a lower maximum quantum yield of PSII, $F_{\mathrm{v}} / F_{\mathrm{m}}$, and an increased capacity and need to dissipate excess excitation energy as NPQ.

For all parameters except $\sigma_{\mathrm{PSII}}$, the results for the $+\mathrm{Fe}$ treatment were significantly different from the respective control (Wilcoxon rank-sum test, $p<0.05$ ), indicating that phytoplankton in the sampled water mass, i.e. the cold waters $<11.5^{\circ} \mathrm{C}$, were Fe-limited. This view is further supported by the low initial $F_{\mathrm{v}} / F_{\mathrm{m}}$ observed for all experiments $(\sim 0.33$, Table 1$)$; a fully dark-regulated $F_{\mathrm{v}} / F_{\mathrm{m}}$ in this range is a widely accepted indicator of Fe limitation in HNLC waters (Boyd and Abraham, 2001; Kolber et al., 1994; Suggett et al., 2009).

The changes in NPQ capacity were diametrically opposite to the changes in $F_{\mathrm{v}} / F_{\mathrm{m}}$ with respect to Fe status: as Fe stress increased, so did the capacity for NPQ. Similar NPQ responses to $\mathrm{Fe}$ status have been observed previously in controlled experiments both in the laboratory and with natural phytoplankton communities from Fe-limited ocean regions (e.g. Alderkamp et al., 2012; Petrou et al., 2014; Schuback et al., 2015; Schuback and Tortell, 2019). While some of these studies reported $\mathrm{NPQ}_{\mathrm{SV}}$, others estimated NPQ $\mathrm{NSV}_{\text {, }}$ hence we decided to investigate the Fe effect on both. Nonphotochemical quenching affects all fluorescence levels and is most easily quantified using the Stern-Volmer parameter- 
ization, which was originally developed for higher plants. However, this parameterization does not take into account differences in $F_{\mathrm{v}} / F_{\mathrm{m}}$ in the dark-regulated state, which can mask differences in NPQ as only the light-induced component is assessed, ignoring differences in basal levels of heat dissipation. The normalized Stern-Volmer parameterization explicitly accounts for differences in $F_{\mathrm{v}} / F_{\mathrm{m}}$, which means it is a more appropriate parameter when samples with different $F_{\mathrm{v}} / F_{\mathrm{m}}$ are being compared, as is the case in our incubations with different levels of Fe stress. However, it is important to note that, mathematically, $\mathrm{NPQ}_{\mathrm{NSV}}$ is inversely related to $F_{\mathrm{v}} / F_{\mathrm{m}}$ when $F_{\mathrm{o}}^{\prime}$ is calculated (see Eq. 4 ) rather than measured directly, as is the case in our study:

$\mathrm{NPQ}_{\mathrm{NSV}}=\frac{F_{\mathrm{o}}}{F_{\mathrm{m}}^{\prime}} / \frac{F_{\mathrm{v}}}{F_{\mathrm{m}}}$

This inverse mathematical relationship, in conjunction with the established sensitivity of $F_{\mathrm{V}} / F_{\mathrm{m}}$ to Fe limitation (Boyd and Abraham, 2001; Kolber et al., 1994; Suggett et al., 2009), means that $\mathrm{NPQ}_{\mathrm{NSV}}$ is not a truly independent parameter with respect to $\mathrm{Fe}$ status, even though the inverse relationship with $F_{\mathrm{v}} / F_{\mathrm{m}}$ may be physiologically relevant. Further-

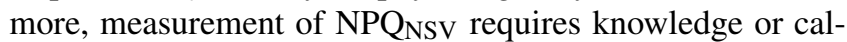
culation of $F_{\mathrm{o}}$ or $F_{\mathrm{o}}^{\prime}$ (Eqs. 3-5), which means it can only be measured with an active fluorometer, such as a FRRf. Conversely, parameters analogous to the NPQsv parameter can be estimated with any fluorometer so long as a dark-regulated and light-regulated measurement is available.

A physiological relationship between NPQ and Fe stress can be understood conceptually as a result of increased excitation pressure on the reaction centres when Fe is limiting (Schuback et al., 2015). Under Fe stress, there are fewer reaction centres and electron transport chains per chlorophyll because electron transport chains are Fe-expensive (Behrenfeld and Milligan, 2013). More energy is thus funnelled to fewer reaction centres, which causes the increase in $\sigma_{\text {PSII }}$ (Alderkamp et al., 2019; Ryan-Keogh et al., 2017; Strzepek et al., 2012). This arrangement comes at the expense of the ability to deal with fluctuations in light; the system is "less robust". Iron limitation thus increases the need for rapid photoprotection, which can be achieved through an increased capacity for NPQ, as has been observed previously (Schuback et al., 2015; Schuback and Tortell, 2019).

From the data presented above, we conclude that the resident phytoplankton in the colder water mass were indeed $\mathrm{Fe}$-limited (evident in the clear treatment response to $\mathrm{Fe}$ addition, Fig. 2) and that both the NPQ capacity and $F_{\mathrm{v}} / F_{\mathrm{m}}$, as derived from FRRf measurements, responded to changes in $\mathrm{Fe}$ status. While $F_{\mathrm{v}} / F_{\mathrm{m}}$ increased with $\mathrm{Fe}$ addition, the NPQ capacity decreased, consistent with expectations. The observation that the colder water mass exhibited signs of $\mathrm{Fe}$ limitation is also consistent with expectations, as the SAZ, and the SOTS site in particular, has been shown to be seasonally Fe-limited, with limitation increasing towards the end of
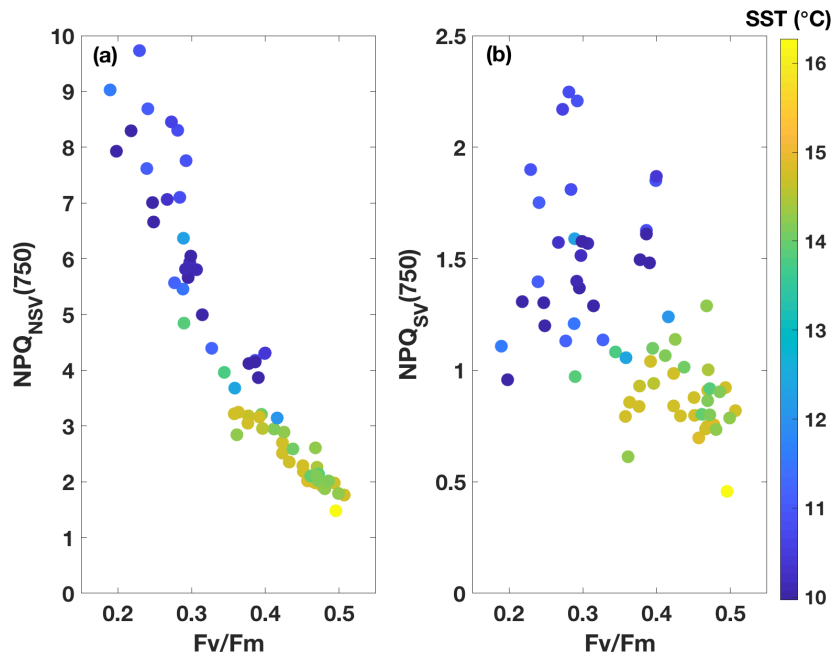

Figure 3. FRRf results from underway samples $(n=66)$. NPQ capacity at a light intensity of $750 \mu \mathrm{molquanta} \mathrm{m}^{-2} \mathrm{~s}^{-1}$ is plotted against $F_{\mathrm{V}} / F_{\mathrm{m}}$, with two different NPQ parameterizations used as follows: normalized Stern-Volmer (a) and Stern-Volmer (b). Colour indicates SST of the corresponding waters.

summer (Boyd et al., 2001; Hutchins et al., 2001; Lannuzel et al., 2011; Sedwick et al., 1999).

\subsection{Underway data: two SST regimes with different ChlF parameters (FRRf)}

Fluorescence measurements similar to the ones carried out on the incubations were also performed on samples taken from the underway seawater line on the SOTS voyage $(n=$ 66). $F_{\mathrm{v}} / F_{\mathrm{m}}$ ranged from 0.2 to 0.5 in the resident phytoplankton and showed an inverse relationship with NPQ capacity (Fig. 3), as was observed for the incubations. The trends in ChlF parameters appeared to fall into two groups based on sea surface temperature (SST): phytoplankton in the colder water mass $\left(<11.5^{\circ} \mathrm{C}\right)$ showed lower $F_{\mathrm{v}} / F_{\mathrm{m}}$ and higher NPQ capacity, consistent with increased Fe limitation, compared to the phytoplankton in the warmer water mass $\left(>13.5^{\circ} \mathrm{C}\right.$ ). Grouping the ChlF parameters based on SST illustrates this point even further (Fig. 4): $F_{\mathrm{v}} / F_{\mathrm{m}}$, as well as the capacity to dissipate excess excitation energy (estimated as NPQNSV and NPQ ${ }_{S v}$ ), was significantly different between the two water masses ( $p \ll 0.01$, Wilcoxon rank-sum test). It thus appears that the phytoplankton in the two SST regimes experienced different levels of Fe stress, but before such a conclusion can be drawn, a number of confounding factors must be discussed, including species composition, mixedlayer depth and the effect of temperature on physiology. 

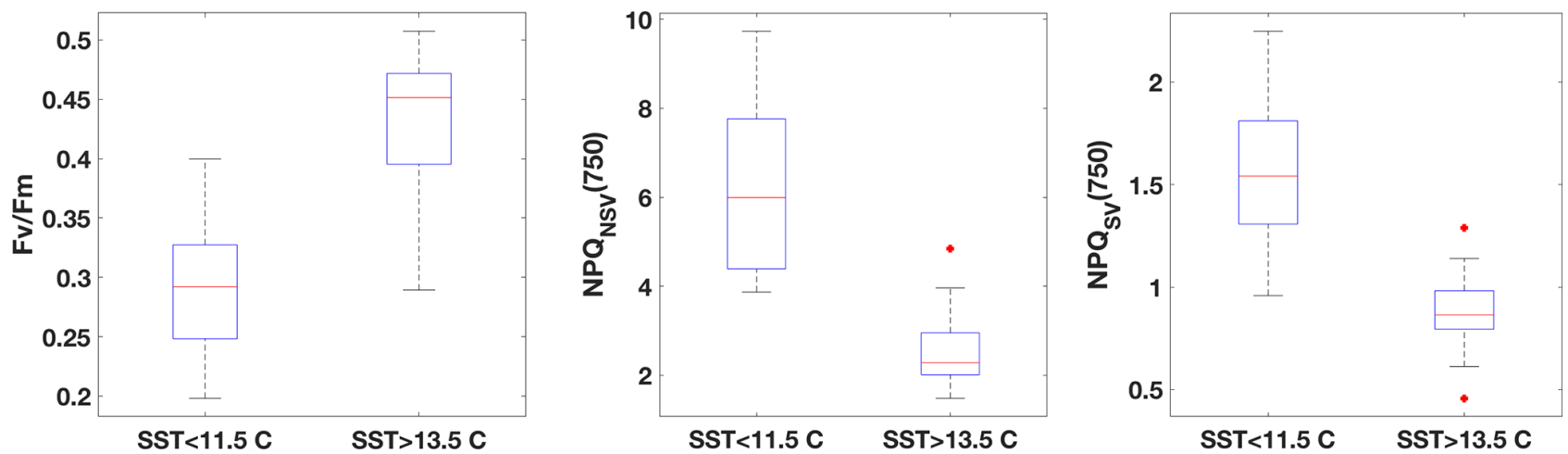

Figure 4. Comparison of FRRf data from underway samples, grouped based on SST. All parameters are significantly different between the two respective water masses (Wilcoxon rank-sum test, $p \ll 0.01$ ).

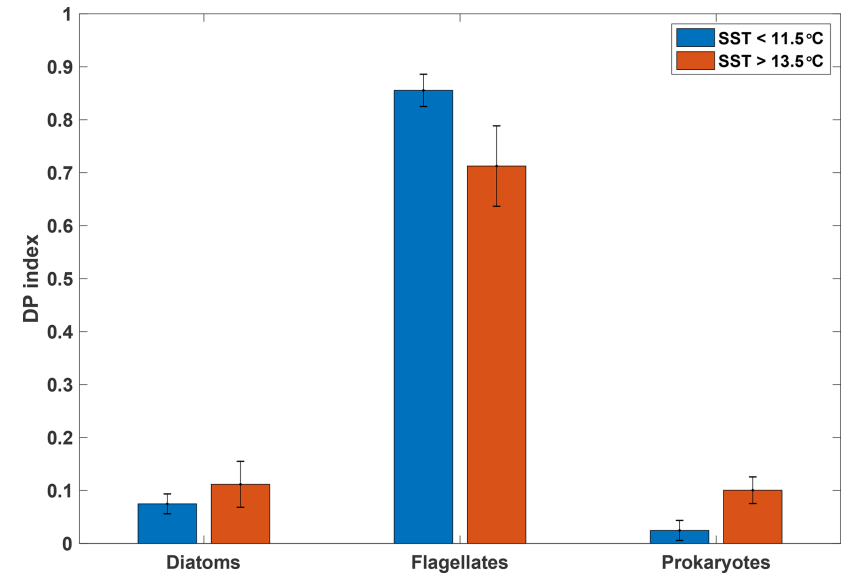

Figure 5. Mean diagnostic pigment (DP) indices calculated based on pigment ratios from HPLC analyses for samples taken from the underway seawater supply, grouped by SST $(n=6$ for SST $>$ $13.5^{\circ} \mathrm{C} ; n=7$ for $\left.\mathrm{SST}<11.5^{\circ} \mathrm{C}\right)$. Error bars indicate 1 standard deviation. See Sect. 2.4.2 for calculation of the DP index.

\subsubsection{Phytoplankton pigments and community composition in the two SST regimes}

The diagnostic pigment (DP) index, calculated from HPLC pigment analyses, provides a simple though not definitive means of investigating phytoplankton community composition. It focusses on three major groups (diatoms, flagellates and cyanobacteria) selected on the basis of their significance rather than their respective size ranges (Barlow et al., 2008). Such a diagnostic index is naturally a simplification and should be treated with caution. However, the DP index has been used across a number of ecological ocean regions, including the SAZ and Southern Ocean, where it compared favourably to the more elaborate CHEMTAX analyses (e.g. Mendes et al., 2015).

Our analysis indicates a dominance of flagellates in both the warm and cold SST regimes, with diatoms and prokaryotes playing a lesser role (Fig. 5). Despite some differences between the two SST regimes, the overall pattern is similar, indicating that the phytoplankton assemblages in the two water masses were comparable (see Figs. S5 and S6 for detailed pigment and phytoplankton absorption results). Moreover, these distributions among major phytoplankton groups are consistent with the phytoplankton community composition in the SAZ reported by Mendes et al. (2015) using similar methods. These authors also conducted a CHEMTAX analysis of their data that suggested a dominance of haptophytes in the SAZ, with pelagophytes, prasinophytes and diatoms making up the majority of other taxa. A recent microscopic analysis of fortnightly samples from a remote sampler on the SOTS mooring at $47^{\circ} \mathrm{S}, 142^{\circ}$ E likewise indicated that flagellates were the most abundant phytoplankton group between September and April, followed by diatoms (Eriksen et al., 2018). The results from the DP index analysis are thus consistent with previous estimates for the region and show that the two SST regimes were broadly similar with respect to phytoplankton community composition.

\subsubsection{Mixed-layer depths and average light field}

The depth of the mixed layer can have a profound impact on NPQ capacity, as phytoplankton acclimate to their light exposure. Deeper mixed layers, resulting in stronger fluctuations in light availability, have been found to increase the NPQ capacity of phytoplankton in the field and under simulated conditions in the laboratory (Browning et al., 2014; Milligan et al., 2012). In our study region, the mixed-layer depth was deepest in the warm SST regime ( $\sim 100 \mathrm{~m}$; Fig. S7), while it ranged between 20 and $90 \mathrm{~m}$ in the colder regime. The corresponding median daily integrated PAR in the mixed layer (for a nominal clear-sky day in March and with PAR attenuation estimated as a function of Chl $a$ based on Morel et al., 2007) was $0.13 \mathrm{~mol} \mathrm{~m}^{-2} \mathrm{~d}^{-1}$ for the warm SST regime, while it ranged from 0.5 to $15 \mathrm{~mol} \mathrm{~m}^{-2} \mathrm{~d}^{-1}$ for the cold SST regime. If the rates and magnitude of light intensity fluctuations were the drivers for the observed differences in NPQ capacity between the two water masses, we would expect the 
warmer water mass (with the deep mixed layer) to show increased NPQ capacity. However, the observed NPQ trend is exactly the opposite, with higher NPQ capacity evident in the colder water mass. With only one CTD station in the warmer SST regime, we may have under-sampled this water mass, but it is unlikely that it showed overall shallower mixed layers than the cold-water regime. We thus conclude that the observed trend in NPQ capacity can not be explained by the mixed-layer depths encountered.

\subsubsection{Temperature effects on phytoplankton photophysiology}

It is well established that temperature has a strong effect on phytoplankton growth, especially with respect to the optimal niche for a given species (e.g. Boyd et al., 2013; Davison, 1991; Raven and Geider, 1988). However, the maximum quantum yield of PSII, $F_{\mathrm{v}} / F_{\mathrm{m}}$, appears less sensitive to temperature. Manipulative studies have reported little or no effect on $F_{\mathrm{v}} / F_{\mathrm{m}}$ for phytoplankton grown at temperatures differing by $4-8{ }^{\circ} \mathrm{C}$ between minimum and maximum temperature (e.g. Kulk et al., 2012; Rose et al., 2009). Indeed, the latter study specifically investigated the synergistic effects of $\mathrm{Fe}$ and temperature on Antarctic phytoplankton. An increase in temperature by $4{ }^{\circ} \mathrm{C}$ did not result in any change of $F_{\mathrm{v}} / F_{\mathrm{m}}$ compared to the control, but an addition of Fe increased $F_{\mathrm{v}} / F_{\mathrm{m}}$ significantly - with and without an increase in temperature (Rose et al., 2009). We thus conclude that it is highly likely that the differences in $F_{\mathrm{v}} / F_{\mathrm{m}}$ and NPQ capacity we observed between the two SST regimes (with mean SSTs of $10.8 \pm 0.5$ and $14.6 \pm 0.7^{\circ} \mathrm{C}$, respectively) were the result of physiological changes in the phytoplankton due to their nutritional $(\mathrm{Fe})$ status, rather than being caused by the different ambient temperatures.

\subsubsection{The case for differences in physiological status in the two SST regimes}

The strongest indicator that the two SST regimes held phytoplankton communities with different levels of $\mathrm{Fe}$ stress is the difference in $F_{\mathrm{v}} / F_{\mathrm{m}}$ between the two regimes (Fig. 4). The decrease in $F_{\mathrm{v}} / F_{\mathrm{m}}$ in the colder water mass corresponded to a large increase in $F_{\mathrm{o}}$ relative to the warm regime (Fig. S8), in line with the hypothesis that under Fe limitation damaged and/or disconnected light-harvesting complexes contribute to background fluorescence, as has been previously observed (Behrenfeld and Milligan, 2013). The corresponding increase in $F_{\mathrm{m}}$ in the presumably Fe-limited water mass is also not unexpected and has been observed in other Fe-limited regions (e.g. Behrenfeld and Kolber, 1999).

Rates of water-column-integrated net primary productivity measured in the cold SST regime also point to Fe limitation in that water mass. Column-integrated primary production rates ranged from $317 \pm 30 \mathrm{mg} \mathrm{Cm}^{-2} \mathrm{~d}^{-1}$ (18 March 2018) to $500 \pm 104 \mathrm{mg} \mathrm{C} \mathrm{m}^{-2} \mathrm{~d}^{-1}$ (7 March 2018). These rates agree well with those measured at the SOTS site in March 2016 using the same method $\left(670 \pm 25 \mathrm{mg} \mathrm{C} \mathrm{m}^{-2} \mathrm{~d}^{-1}\right)$ (Ellwood et al., 2020) but are considerably lower than those measured by Westwood et al. (2011) in subantarctic waters in austral summer (January-February 2007) when Fe concentrations are higher: $1034-1627 \mathrm{mg} \mathrm{Cm}^{-2} \mathrm{~d}^{-1}$. While part of the difference between our results and those of Westwood et al. (2011) may be due to methodological differences, i.e. short $(2 \mathrm{~h})$ versus long $(24 \mathrm{~h}){ }^{14} \mathrm{C}$ incubations, we ascribe most of the difference to the seasonal cycle of Fe limitation observed previously for SOTS (Boyd et al., 2001; Hutchins et al., 2001; Lannuzel et al., 2011; Sedwick et al., 1999). See the Supplement for a full comparison of observed conditions between this study and Westwood et al. (2011).

Fewer ancillary data are available for the warmer water mass, as there were no primary productivity measurements or Fe-addition experiments undertaken. However, macronutrient data from the one CTD in that water mass indicate that the warm SST regime was not high nutrient-low chlorophyll (HNLC), as $\mathrm{NO}_{x}$ was drawn down to near zero, which was not the case for the colder waters where $\mathrm{NO}_{x}$ was always well above $5 \mu \mathrm{M}$ (Fig. S9). Phosphate concentrations were also significantly lower in the warmer waters than the cold waters, while silicate was depleted for both.

The SST map in Fig. 1 indicates that the warm SST signature near SOTS was part of a cyclonic eddy, which could be tracked back in time to even warmer waters southwest of Tasmania based on its signature on satellite altimetry and SST images (not shown). At the time of sampling, the eddy-associated water mass exhibited SSTs reaching $>$ $14{ }^{\circ} \mathrm{C}$, compared to $<12{ }^{\circ} \mathrm{C}$ for the waters further west, and showed warmer and saltier water throughout the water column, with a salinity minimum around 34.4 (Fig. S10). Such a temperature-salinity signature is consistent with an origin of the eddy-associated water mass either east or west of Tasmania, with a strong influence from the Tasman Sea (HerraizBorreguero and Rintoul, 2011). Waters east of Tasmania have previously been found to be Fe-replete (and low in nitrate), with airborne dust and shelf sediments presumed to be the main Fe sources (Bowie et al., 2009; Lannuzel et al., 2011). $F_{\mathrm{v}} / F_{\mathrm{m}}$ values indicative of Fe sufficiency $(\sim 0.5)$ were also reported for the SAZ southeast of Tasmania $\left(\mathrm{SST} \sim 15^{\circ} \mathrm{C}\right.$ ) in late summer, along with very low nitrate and non-limiting Fe concentrations at the surface (Hassler et al., 2014). It is thus highly likely that the warmer water mass encountered during the SOTS voyage in 2018 was Fe-replete, while the colder water mass was Fe-limited. The absence of dissolved $\mathrm{Fe}$ data leaves the $\mathrm{Fe}$ nutritional status of the warmer water mass community less than completely clear (although the presence of $F_{\mathrm{v}} / F_{\mathrm{m}}$ values above 0.4 suggests Fe limitation was unlikely since $\mathrm{Fe}$ status is known to be the dominant driver for $F_{\mathrm{v}} / F_{\mathrm{m}}$ in the Southern Ocean, e.g. Suggett et al., 2009). Regardless of this uncertainty, the Fe-limited status and corresponding high NPQ capacity of the cold-water community is clear. 

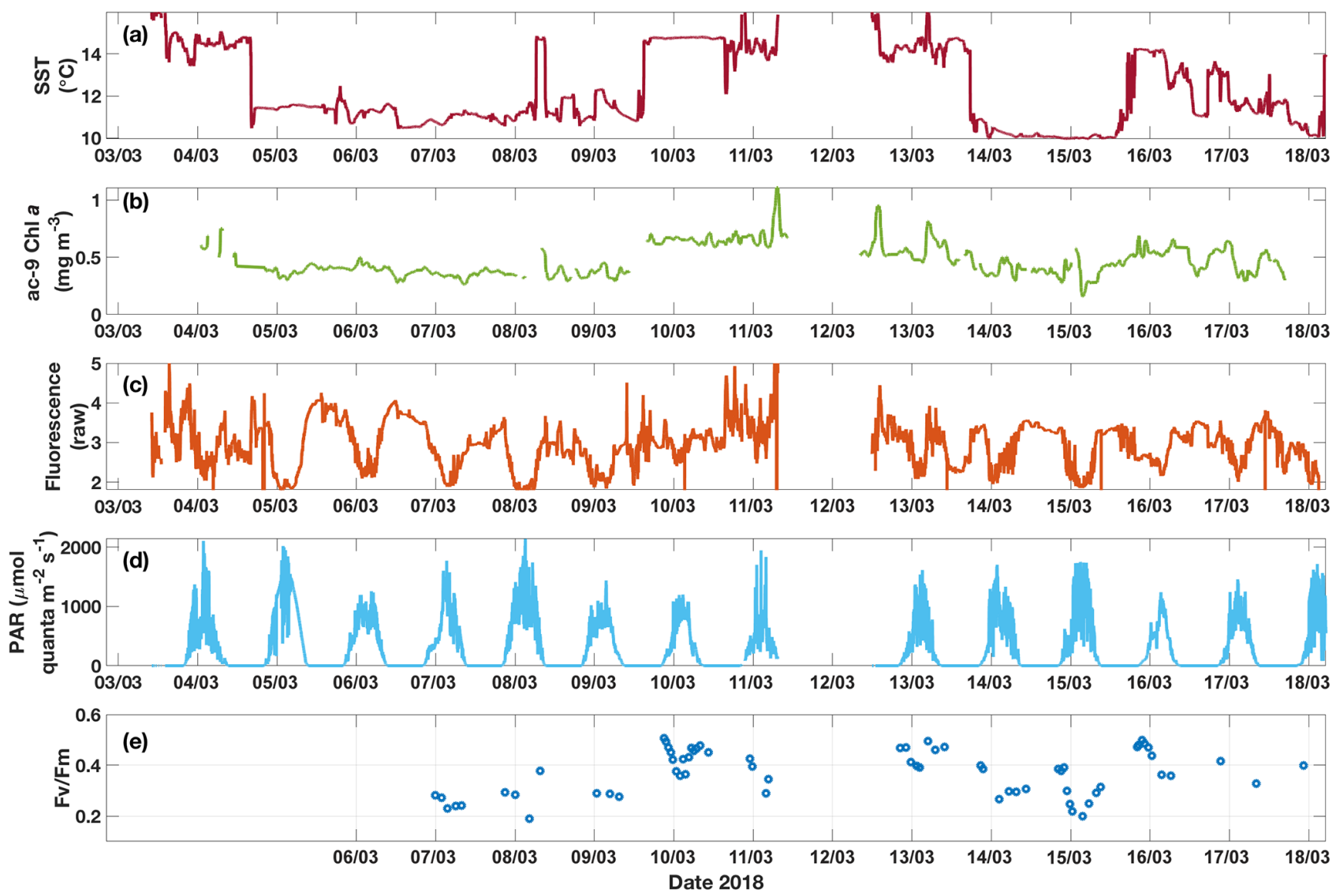

Figure 6. Time series for underway data from the SOTS voyage in 2018 of (a) SST, (b) Chl $a$ from ac-9, (c) raw fluorescence, (d) abovewater PAR and (e) $F_{\mathrm{V}} / F_{\mathrm{m}}$ measured on dark-acclimated discrete samples. Diel fluctuations in fluorescence are apparent, especially when cold water was sampled. These fluctuations are not found in the corresponding Chl $a$ time series. Note that the data gap around 12 March is due to the ship leaving the SAZ region during that time.

\subsection{Underway data: continuous measurements across the two SST regimes}

The two SST regimes were repeatedly visited by the ship during the voyage (Fig. 6). The Chl $a$ data from the ac-9 were remarkably different from the fluorometer traces (compare Fig. $6 \mathrm{~b}$ and c), with clear day-night fluctuations in the latter that were not reflected in the ac-9 data. These fluctuations were especially pronounced in the colder water mass, which had overall lower Chl $a$ concentrations than the warmer waters (mean Chl $a=0.38 \pm 0.06 \mathrm{mg} \mathrm{m}^{-3}$ for SST $<11.5^{\circ} \mathrm{C}$ and $0.62 \pm 0.11 \mathrm{mg} \mathrm{m}^{-3}$ for SST $>13.5^{\circ} \mathrm{C}$ ). The daily fluorescence minima coincided with the maxima in above-water incident PAR and vice versa; i.e. fluorescence was highest during the night. Such daily fluorescence cycles are consistent with non-photochemical quenching of fluorescence in the daytime.

\subsubsection{Physiological information in underway fluorescence: NPQ differences between the two SST regimes}

In order to investigate NPQ as measured with the standard fluorometer (Fig. 6c) in more detail, we normalized fluorescence by Chl $a$ as estimated by the ac- 9 and plotted it against incident daytime PAR (Fig. 7). Colour-coding by SST clearly shows that two NPQ regimes were at play. In the colder waters, F/Chl $a$ was high at low PAR and decreased considerably as PAR increased - dynamic NPQ was high. In the warmer waters, F/Chl $a$ was relatively constant across PAR values and dynamic NPQ was thus low. Note that normalization to $\mathrm{Chl} a$ removes differences in the fluorescence signal that would be caused by differing $\mathrm{Chl} a$ concentrations in the water masses.

The NPQ signal from the standard fluorometer was further investigated by formally separating the data from the two water masses based on SST (Fig. 8). A loess filter was applied to the respective pooled data sets (for values measured at PAR $>5$ and PAR $<1000 \mu$ molquanta $\mathrm{m}^{-2} \mathrm{~s}^{-1}$ ), 


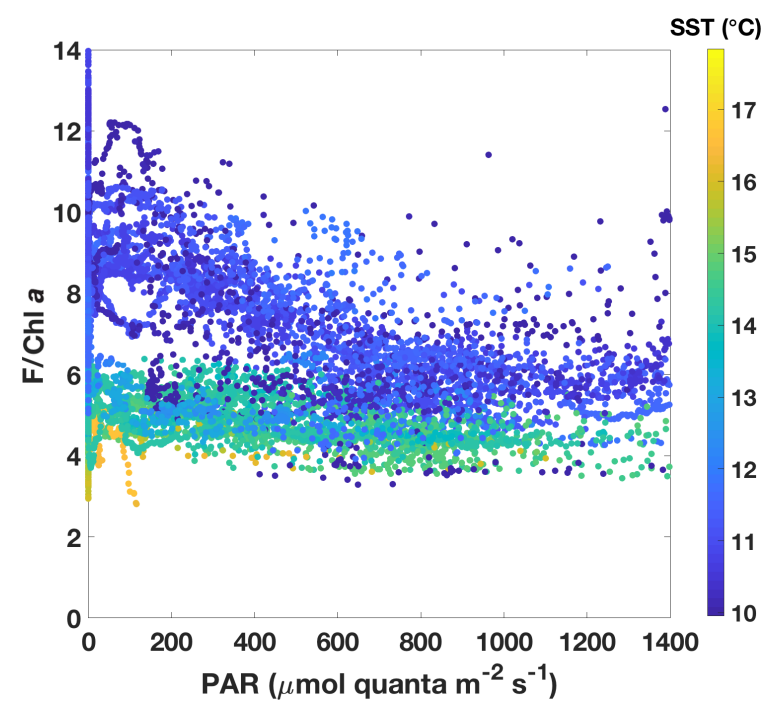

Figure 7. Underway fluorescence data normalized to Chl $a$ plotted against incident PAR above the surface. Chl $a$ was estimated from ac-9 data. Data points are colour-coded according to SST.

and NPQ $\mathrm{SF}$ (NPQ measured with a standard fluorometer) was estimated from the filtered data according to Eq. (6). The $\mathrm{NPQ}_{\mathrm{SF}}$ signal in the colder, HNLC water mass was more than twice as high as that in the warm SST regime, and a similar trend was discernible even without normalization of the fluorescence signal to Chl $a$ (Fig. 8). The trends in NPQ as evidenced in the data from the standard fluorometer are thus consistent with the NPQ capacities measured with the FRRf (Fig. 4): increased dynamic NPQ (and NPQ capacity) in the colder waters relative to the warm SST regime. This result is significant as it indicates that measurements from a standard fluorometer can be interpreted with regards to phytoplankton physiological status. Without the control afforded by an FRRf, simply using a standard fluorometer and the daily cycle of the sun, a signal is measured $\left(\mathrm{NPQ}_{\mathrm{SF}}\right)$ that holds profound physiological information. This should not come as a complete surprise, as it has long been recognized that standard fluorometers are affected by NPQ, and considerable research has gone into investigating how to best correct for NPQ in order to retrieve more accurate profiles of Chl $a$ concentration (Biermann et al., 2015; Thomalla et al., 2018; Xing et al., 2012, 2018). However, given the dependence of NPQ on incident irradiance, attempts to correct for it in a "physiological" way have tended to be based on irradiance thresholds or light history (e.g. Behrenfeld et al., 2009; Xing et al., 2018), while ignoring other factors affecting phytoplankton physiological status, such as Fe limitation.

A noteworthy exemption is the study by Browning et al. (2014), which specifically investigated the variability of NPQ along eco-physiological gradients in the Southern Ocean. That study showed similar trends to ours: increased dynamic NPQ was associated with Fe-limited waters of the
Antarctic Circumpolar Current, while subtropical gyre-type waters, where $\mathrm{Fe}$ was replete and nitrogen was low, exhibited subdued NPQ. Overall, they found that their NPQ parameterization showed the strongest correlation with SST, which they interpreted to be largely caused by the relationship between SST and the extent of near-surface stratification and mixed-layer depth (Browning et al., 2014). They also found a correlation between NPQ and $F_{\mathrm{v}} / F_{\mathrm{m}}$ that was statistically significant at the $p<0.001$ confidence level but was weaker than that with SST. It is worth pointing out that there were significant methodological differences between their approach and ours, as well as a much larger SST gradient in their study region $\left(3-25^{\circ} \mathrm{C}\right)$, which likely has its own correlation with $\mathrm{Fe}$ limitation while also causing differences in species composition that can have a strong influence on $F_{\mathrm{v}} / F_{\mathrm{m}}$ (Suggett et al., 2009). Regardless of the cause in NPQ variability, our findings reinforce the observation by Browning et al. (2014) that NPQ can be highly variable due to factors other than incident PAR, implying that NPQ corrections that rely solely on PAR should be viewed with caution.

Overall, our results are consistent with the differences in NPQ observed in the two SST regimes being caused by differences in their Fe limitation status, as evidenced in the respective $F_{\mathrm{v}} / F_{\mathrm{m}}$, with implications for the expected efficiency of photochemistry. Not only did we find a strong inverse relationship between $F_{\mathrm{v}} / F_{\mathrm{m}}$ and NPQ capacities estimated with an FRRf light-curve protocol, but the relationship was also borne out in $\mathrm{NPQ}_{\mathrm{SF}}$ measured with a standard fluorometer - an instrument type frequently used on moorings, ships and autonomous measuring platforms, such as Argo floats. We have thus shown that measurements from a standard fluorometer can provide useful information on phytoplankton physiology, in particular the presence of Fe stress. While the phytoplankton community in our study was dominated by flagellates (Fig. 5), we expect that our results hold across a range of phytoplankton species, as the relationship between NPQ and Fe limitation status has been observed in laboratory and field studies elsewhere, including phytoplankton communities dominated by diatoms (Schuback et al., 2015; Schuback and Tortell, 2019).

\subsection{Case study: application of $\mathrm{NPQ}_{\mathrm{SF}}$ approach to mooring data}

In order to further test the utility of this interpretation of fluorescence measured with a standard fluorometer, we investigated NPQSF on a time series from the SOTS mooring (Fig. 9a). Here, NPQSF was estimated based on daily fluorescence measurements, after application of a smoothing filter (see Sect. 3.3.1). Due to differences in the maximum PAR on any given day, one could argue that $\mathrm{NPQ}_{\mathrm{SF}}$ should be normalized by the incident PAR at $F_{\min }$, as the depression in fluorescence is expected to be proportional to the incident light. Such a measure decreases the scatter in the time series but preserves the overall trend observed in Fig. 9a (Fig. S11). 

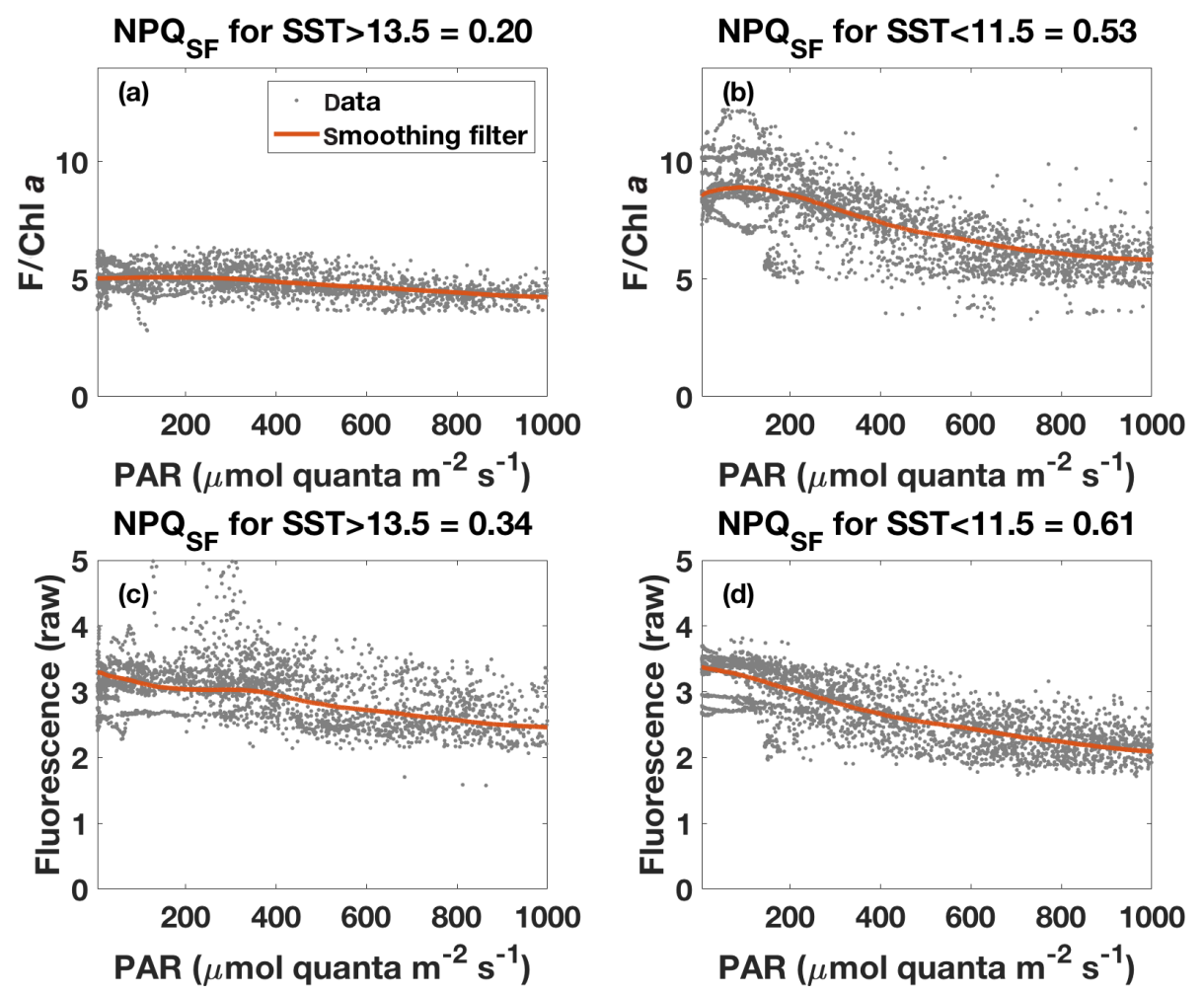

Figure 8. Fluorescence-PAR relationship as in Fig. 7 but with data grouped according to the respective SST (grey dots) and with a robust loess smoothing filter applied to the ordered data (red). Note that data for PAR $<5 \mu$ molquanta $\mathrm{m}^{-2} \mathrm{~s}^{-1}$ are not shown. Panels (a) and (b) show the results for fluorescence normalized to $\mathrm{Chl} a$ (estimated based on ac-9 data), while panels (c) and (d) show results for unnormalized fluorescence. $\mathrm{NPQ}_{\mathrm{SF}}$ was calculated according to Eq. (6) using the smoothed data, with $F_{\max }$ the maximum fluorescence for PAR $>5$ and PAR $<1000 \mu$ mol quanta $\mathrm{m}^{-2} \mathrm{~s}^{-1}$, while $F_{\min }$ was taken as the minimum fluorescence for that range.

Note that noise in $\mathrm{NPQ}_{\mathrm{SF}}$ is likely related to both fluctuating light conditions day to day and patchiness in phytoplankton fields. The fluorometer on the SOTS mooring measured once every hour, so only a very limited number of data points were available for any given day. The passages of small fronts and phytoplankton patches would thus have a large impact on the trends observed in a day, confounding the NPQ signal.

In the context of the ancillary measurements (Fig. 9), the trends observed in $\mathrm{NPQ}_{\mathrm{SF}}$ over the growing season appear sensible. Some connection with changes in the MLD is apparent, for example a decrease in $\mathrm{NPQ}_{\mathrm{SF}}$ in November as the mixed-layer shoals, but the MLD dynamics cannot explain fluctuations in NPQSF over the summer. Nor does the light field experienced within the mixed layer (Fig. 9c) show a clear relationship with NPQSF. However, there is an interesting connection with the dynamics in $\mathrm{Chl} a$ concentrations: $\mathrm{NPQ}_{\mathrm{SF}}$ is relatively low in spring and remains low, with some fluctuations, until Chl $a$ peaks in mid-January. After this peak, Chl $a$ decreases and NPQ could indicate the onset of Fe limitation at the SOTS mooring late in summer. Indeed, several studies have concluded that the SAZ, in particular the SOTS area, is Fe-limited in summer (Boyd et al., 2001; Hutchins et al., 2001; Lannuzel et al., 2011; Sedwick et al., 1999), with Fe resupply in winter from Ekman transport (Ellwood et al., 2008) and deep mixing (Tagliabue et al., 2014). An interpretation of increased NPQ ${ }_{S F}$ as a response to the onset of Fe limitation is thus supported by the historical data available. Furthermore, we point out that the increase in NPQSF corresponds to an increase in water temperature over the season - the trend is thus opposite to the one seen in the voyage data, where NPQSF was highest in the colder waters. This further supports our contention that the observed trends in $\mathrm{NPQSF}_{\mathrm{SF}}$ (and $F_{\mathrm{V}} / F_{\mathrm{m}}$ ) in the incubations and underway data are not driven by SST changes.

This same time period on the SOTS mooring has also been evaluated based on discrete samples for nutrients and phytoplankton collected by an autonomous sampler (Eriksen et al., 2018). Of the macronutrients, only silicate decreased to concentrations that could be considered limiting $(<1 \mu \mathrm{M}$ at the end of January 2011). This development coincided with a decrease in diatom biovolume relative to other genera that lasted for about a month but began to recover in March 2011 (Eriksen et al., 2018). Overall, the phytoplankton assemblage at SOTS in 2010/2011 was very diverse, with diatoms, dinoflagellates and ciliates figuring most prominently with respect to biovolume. Similarity tests based on abundance in- 

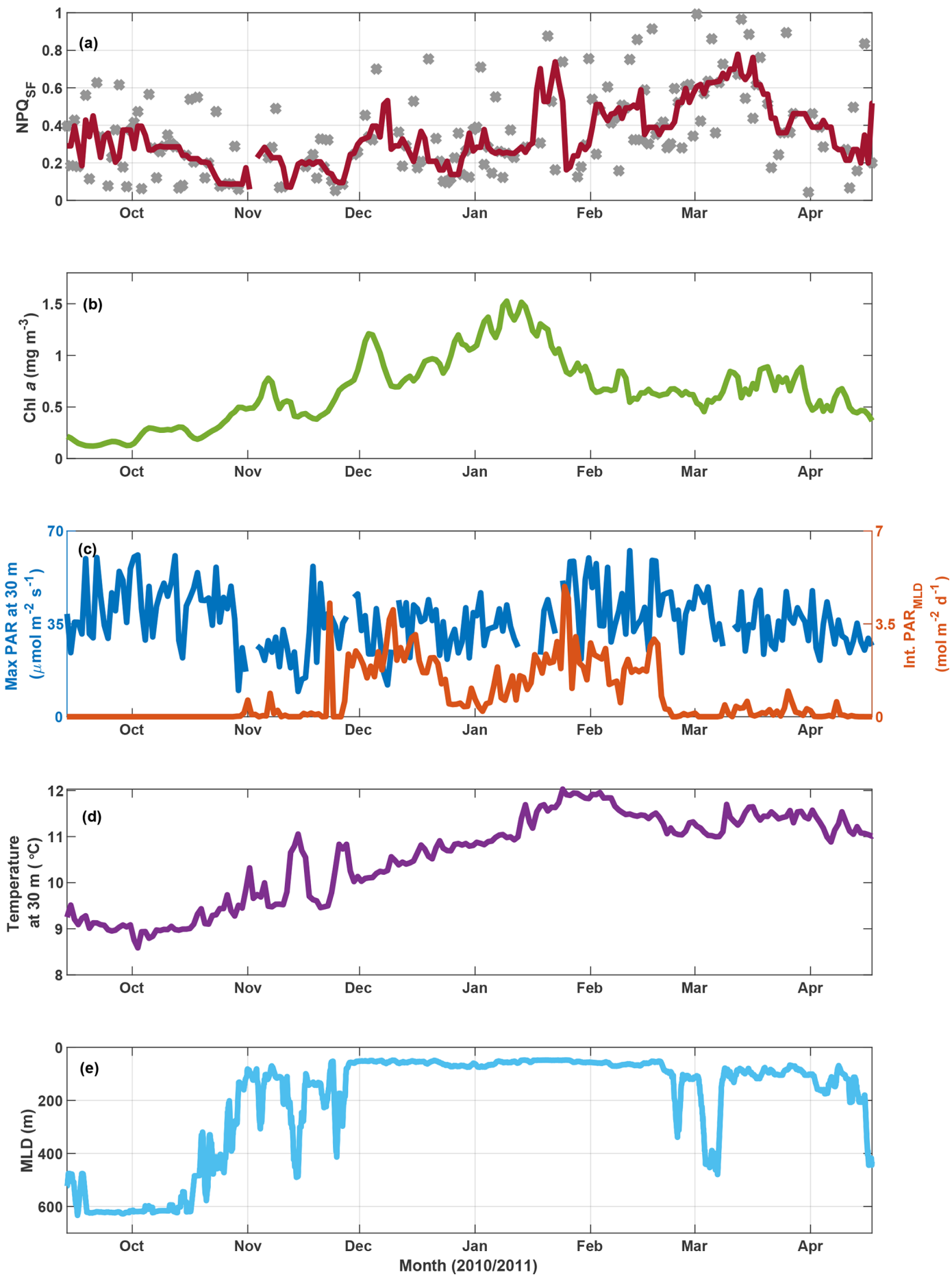

Figure 9. SOTS mooring data for October 2010 to April 2011. Panel (a) shows NPQSF (see Fig. S11 for a version where NPQSF is normalized to PAR at $\left.F_{\min }\right)$, with grey markers indicating daily estimates and the red line a $7 \mathrm{~d}$ running median. Panel (b) shows a three-point running mean over daily $\mathrm{Chl} a$ concentrations estimated based on calibrated fluorescence. Panel (c) shows maximum PAR recorded at $30 \mathrm{~m}$ for any given day (left axis) and the integrated daily PAR for the mixed layer (right axis), with incident PAR calculated based on latitude, longitude, time of year, and clear-sky conditions; PAR attenuation estimated as a function of Chl $a$ based on Morel et al. (2007); and MLD as in panel (e). Water temperature at $30 \mathrm{~m}$ is shown in panel (d), and the mixed-layer depth is indicated in panel (e) (see Sect. 2.6 for details). 
dicated a spring community that was present until the end of 2010 , followed by a summer community until the end of February and an autumn community thereafter (Eriksen et al., 2018). The observed fluctuations in NPQSF can thus not be tied to distinct changes in phytoplankton community.

To sum up, the findings from the SOTS mooring for the 2010/2011 season support our argument that NPQSF may hold information on phytoplankton physiology, as the observed fluctuations in NPQSF cannot be explained by developments in seasonal MLD, SST, light experienced in the mixed layer, or phytoplankton community composition. Rather, they exhibit a trend that is consistent with historical studies in the SAZ that have observed Fe limitation developing in summer and into autumn (see above), which could lead to an increased need for photoprotection, as evidenced in higher NPQSF.

\section{Conclusions and future work}

This study has explored the connection between NPQ and phytoplankton physiological status as indicated by $F_{\mathrm{v}} / F_{\mathrm{m}}$ in an HNLC region. The results suggest that the variability observed in NPQ - mirroring changes in $F_{\mathrm{v}} / F_{\mathrm{m}}$ - was driven by different levels of Fe limitation. A range of NPQ parameters was assessed, measured with both an active fluorometer (FRRf) and a standard fluorometer mounted on the underway seawater supply of a research vessel. The relationship between NPQ and Fe limitation was tested with incubation experiments, where Fe concentrations were controlled by adding $\mathrm{Fe}$ and a strong Fe-binding ligand. All experiments showed a statistically significant relationship between Fe status and NPQ capacity as measured with an FRRf (Fig. 2), as has been observed previously (Schuback et al., 2015; Schuback and Tortell, 2019). Our analysis is novel in that it uses a standard fluorometer (such as is conventionally used to monitor Chl $a$ concentrations) to derive the NPQ parameter $\mathrm{NPQ}_{\mathrm{SF}}$, linking its variability to phytoplankton physiology, i.e. Fe limitation status. Furthermore, application of the proposed methodology to data from a standard fluorometer on the SOTS mooring shows that the derived NPQSF exhibits a pattern that is consistent with the expected seasonal development of Fe limitation at the site. The approach may thus be promising for the interpretation of standard fluorometer data from HNLC regions, allowing assessment of the relative changes in Fe limitation status along voyage transects and mooring time series. Interpretation of fluorescence data in this way will be improved by independent assessments of Chl $a$ concentration, such as can be achieved with an ac-9. Normalization by $\mathrm{Chl} a$ (or phytoplankton absorption) removes the influence of $\mathrm{Chl} a$ concentration on the fluorescence signal, thus refining the NPQ signal. Overall, our results point to a novel approach for the interpretation of widely available fluorescence sensor data to assess the role of Fe sufficiency in phytoplankton physiology, and thus productivity, in the Southern Ocean.

Ultimately, this approach to fluorescence has the potential to be applied to data from autonomous floats in the Southern Ocean, such as the biogeochemical (BGC) Argo fleet. A recent application to glider data from the SAZ in the Atlantic Ocean has allowed identification of regions and time periods where Fe limitation was relieved (Ryan-Keogh and Thoma1la, 2020). Studies of this kind will improve our understanding of biogeochemical cycles in the understudied Southern Ocean. However, care will undoubtedly be needed in the interpretation of large spatial variations (e.g. when crossing fronts) owing to differences in species composition and mixing regimes.

Future work should include laboratory experiments under fluctuating light conditions, i.e. mimicking mixing in the ocean, to further probe the interplay of light history and $\mathrm{Fe}$ status on NPQ and how both affect phytoplankton growth. Care should be taken to not only focus on steady-state scenarios but to also include perturbation experiments, as relaxation of Fe limitation in the Southern Ocean may be a sporadic event, for example if storm-induced deep mixing or dust deposition are the means of Fe fertilization. Overall, assessment of the level of Fe limitation is less interesting than the question of how this limitation affects primary production and growth rate, as these are the quantities that will be felt throughout the ecosystem. The eventual goal would thus be to establish a link between a readily measurable proxy, such as NPQ achieved by further investigations into the relationship between NPQ and the maximum quantum yield of photosynthesis, which has been shown to respond to Fe fertilization (Alderkamp et al., 2019; Hiscock et al., 2008) and has also been incorporated into a new global model of net primary production, albeit currently as a function of light acclimation only (Silsbe et al., 2016).

Data availability. Surface geostrophic velocities were downloaded from the AODN data portal at https://portal.aodn.org. au (last access: 12 December 2018) (IMOS/CSIRO, 2018). All voyage data (except FRRf and ac-9) are freely available from the CSIRO Data Trawler: https://www.cmar.csiro.au/ data/trawler/survey_details.cfm?survey=IN2018_V02 (last access: 21 June 2018) (MNF, 2018). The mooring data are freely available via the Australian Ocean Data Network portal: https://portal. aodn.org.au (last access: 12 December 2018). FRRf and ac-9 data are available directly from the corresponding author and can be requested by email: christina.schallenberg@utas.edu.au.

Supplement. The supplement related to this article is available online at: https://doi.org/10.5194/bg-17-793-2020-supplement. 
Author contributions. CS conceived the idea for the study and designed and carried out the experimental work on the voyage, except for ${ }^{14} \mathrm{C}$ uptake experiments, which were done by RFS. CS processed and analysed all data post-voyage with the following exceptions: phytoplankton pigment and filter pad absorption measurements were undertaken and interpreted by LAC and the results of ${ }^{14} \mathrm{C}$ uptake experiments were analysed by RFS. TWT leads the Southern Ocean Times Series facility, which provided the moored sensor observations. The details of the inquiry were significantly improved through discussions with RFS, NS, TWT and PWB. CS wrote the majority of the manuscript, with refinements and additions provided by all co-authors.

Competing interests. The authors declare that they have no conflict of interest.

Acknowledgements. We thank the captains and crews of RV Investigator and RV Southern Surveyor and the Marine National Facility for their support. Special thanks to Julie Janssens for manning the ac-9 during night shift and to Peter Jansen for help with the mooring data. Diana Davies and the CSIRO Moored Sensor Systems team were indispensable for the mooring and voyage field programs, and we are grateful for all their hard work and good cheer. Finally, we thank Peter Hughes and Julie Janssens for nutrient analyses and hydrochemistry support and Eleanor Haigh for paving the way to NPQ analyses on the mooring data.

Financial support. Christina Schallenberg was supported by a Canadian National Sciences and Engineering Research Council (NSERC) postdoctoral fellowship (grant no. PDF-502793-2017) and by the Antarctic Climate and Ecosystems Cooperative Research Centre (ACE CRC) at the University of Tasmania. The Southern Ocean Time Series autonomous moored observatory is a facility of the Australian Integrated Marine Observing System and also received support from the ACE CRC, the Australian Antarctic Science Program and the Australian Marine National Facility. Robert F. Strzepek and Philip W. Boyd received support from the ACE CRC and the Antarctic Gateway Partnership (Australian Research Council).

Review statement. This paper was edited by Koji Suzuki and reviewed by two anonymous referees.

\section{References}

Alderkamp, A.-C., Kulk, G., Buma, A. G. J., Visser, R. J. W., Van Dijken, G. L., Mills, M. M., and Arrigo, K. R.: The effect of iron limitation on the photophysiology of Phaeocystis antarctica (Prymnesiophyceae) and Fragilariopsis cylindrus (Bacillariophyceae) under dynamic irradiance, J. Phycol., 48, 45-59, https://doi.org/10.1111/j.1529-8817.2011.01098.x, 2012.

Alderkamp, A.-C., van Dijken, G. L., Lowry, K. E., Lewis, K. M., Joy-Warren, H. L., van de Poll, W., Laan, P., Gerringa, L., Del- mont, T. O., Jenkins, B. D., and Arrigo, K. R.: Effects of iron and light availability on phytoplankton photosynthetic properties in the Ross Sea. Mar. Ecol. Prog. Ser., 621, 33-50, 2019.

Barlow, R., Kyewalyanga, M., Sessions, H., van den Berg, M., and Morris, T.: Phytoplankton pigments, functional types, and absorption properties in the Delagoa and Natal Bights of the Agulhas ecosystem, Estuar. Coast. Shelf. S., 80, 201-211, https://doi.org/10.1016/j.ecss.2008.07.022, 2008.

Behrenfeld, M. J. and Kolber, Z. S.: Widespread iron limitation of phytoplankton in the South Pacific Ocean, Science, 283, 840844, 1999.

Behrenfeld, M. J. M. and Milligan, A. A. J.: Photophysiological expressions of iron stress in phytoplankton, Ann. Rev. Mar. Sci., 5, 217-246, https://doi.org/10.1146/annurev-marine121211-172356, 2013.

Behrenfeld, M. J., Westberry, T. K., Boss, E. S., O’Malley, R. T., Siegel, D. A., Wiggert, J. D., Franz, B. A., McClain, C. R., Feldman, G. C., Doney, S. C., Moore, J. K., Dall'Olmo, G., Milligan, A. J., Lima, I., and Mahowald, N.: Satellite-detected fluorescence reveals global physiology of ocean phytoplankton, Biogeosciences, 6, 779-794, https://doi.org/10.5194/bg-6-7792009, 2009.

Biermann, L., Guinet, C., Bester, M., Brierley, A., and Boehme, L.: An alternative method for correcting fluorescence quenching, Ocean Sci., 11, 83-91, https://doi.org/10.5194/os-11-83-2015, 2015.

Bowie, A. R., Lannuzel, D., Remenyi, T. A., Wagener, T., Lam, P. J., Boyd, P. W., Guieu, C., Townsend, A. T., and Trull, T. W.: Biogeochemical iron budgets of the Southern Ocean south of Australia: Decoupling of iron and nutrient cycles in the subantarctic zone by the summertime supply, Global Biogeochem. Cy., 23, GB4034, https://doi.org/10.1029/2009GB003500, 2009.

Boyd, P. W. and Abraham, E. R.: Iron-mediated changes in phytoplankton photosynthetic competence during SOIREE, DeepSea Res. Pt. II, 48, 2529-2550, https://doi.org/10.1016/S09670645(01)00007-8, 2001.

Boyd, P. W. and Harrison, P. J.: Phytoplankton dynamics in the NE subarctic Pacific, Deep-Sea Res. Pt. II, 46, 2405-2432, 1999.

Boyd, P. W., Crossley, A. C., DiTullio, G. R., Griffiths, F. B., Hutchins, D. A., Queginer, B., Sedwick, P. N., and Trull, T. W.: Control of phytoplankton growth by iron supply and irradiance in the subantarctic Southern Ocean: Experimental results from the SAZ project, J. Geophys. Res.-Oceans, 106, 31573-31583, 2001.

Boyd, P. W., Jickells, T., Law, C. S., Blain, S., Boyle, E. A., Buesseler, K. O., Coale, K. H., Cullen, J. J., de Baar, H. J. W., Follows, M., Harvey, M., Lancelot, C., Levasseur, M., Owens, N. P. J., Pollard, R., Rivkin, R. B., Sarmiento, J., Schoemann, V., Smetacek, V., Takeda, S., Tsuda, A., Turner, S., and Watson, A. J.: Mesoscale iron enrichment experiments 19932005: Synthesis and future directions, Science, 315, 612-617, https://doi.org/10.1126/science.1131669, 2007.

Boyd, P. W., Rynearson, T. A., Armstrong, E. A., Fu, F., Hayashi, K., Hu, Z., Hutchins, D. A., Kudela, R. M., Litchman, E., Mulholland, M. R., Passow, U., Strzepek, R. F., Whittaker, K. A., Yu, E., and Thomas, M. K.: Marine phytoplankton temperature versus growth responses from polar to tropical waters-outcome of a scientific community-wide study, PLOS ONE, 8, e63091, https://doi.org/10.1371/journal.pone.0063091, 2013. 
Browning, T., Bouman, H., and Moore, C.: Satellite-detected fluorescence: decoupling nonphotochemical quenching from iron stress signals in the South Atlantic and Southern Ocean, Global Biogeochem. Cy., 28, 510-524, https://doi.org/10.1002/2013GB004773, 2014.

Clementson, L. A.: The CSIRO method, in The Fifth SeaWiFS HPLC Analysis Round-Robin Experiment (SeaHARRE5); NASA Technical Memorandum 2012-217503, edited by: Hooker, S. B., Clementson, L., Thomas, C. S., Schlüter, L., Allerup, M., Ras, J., Claustre, H., Normandeau, C., Cullen, J., Kienast, M., Kozlowski, W., Vernet, M., Chakraborty, S., Lohrenz, S., Tuel, M., Redalje, D., Cartaxana, P., Mendes, C. R., Brotas, V., Prabhu Matondkar, S. G., Parab, S. G., Neeley, A., and Skarstad Egeland, E., NASA Goddard Space Flight Center, Greenbelt, Maryland, 2013.

Davison, I. R.: Environmental effects on algal photosynthesis: temperature, J. Phycol., 27, 2-8, 1991.

Demmig-Adams, B., Garab, G., Adams III, W., and Govindjee (Eds.): Non-Photochemical Quenching and Energy Dissipation in Plants, Algae and Cyanobacteria, Springer, Dordrecht Heidelberg New York London, https://doi.org/10.1007/978-94-0179032-1, 2014.

Ellwood, M. J., Boyd, P. W., and Sutton, P.: Winter-time dissolved iron and nutrient distributions in the Subantarctic Zone from 40-52 S; 155-160E, Geophys. Res. Lett., 35, L11604, https://doi.org/10.1029/2008GL033699, 2008.

Ellwood, M. J., Strzepek, R. F., Strutton, P. G., Trull, T. W., Fourquez, M., and Boyd, P. W.: Distinct iron cycling in a Southern Ocean eddy, Nat. Commun., 11, 825, https://doi.org/10.1038/s41467-020-14464-0, 2020.

Eriksen, R., Trull, T. W., Davies, D., Jansen, P., Davidson, A. T., Westwood, K., and van den Enden, R.: Seasonal succession of phytoplankton community structure from autonomous sampling at the Australian Southern Ocean Time Series (SOTS) observatory, Mar. Ecol. Prog. Ser., 589, 13-31, 2018.

Falkowski, P., Lin, H., and Gorbunov, M.: What limits photosynthetic energy conversion efficiency in nature? Lessons from the oceans, Philos. T. Roy. Soc. B, 372, 2-8, 2017.

Geider, R. J., La Roche, J., Greene, R. M., and Olaizola, M.: Response of the photosynthetic apparatus of Phaeodactylum tricornutum (Bacillariophyceae) to nitrate, phosphate, or iron starvation, J. Phycol., 29, 755-766, 1993.

Greene, R. M., Geider, R. J., Kolber, Z., and Falkowski, P. G.: IronInduced changes in light harvesting and photochemical energyconversion processes in eukaryotic marine algae, Plant Physiol., 100, 565-575, 1992.

Grenier, M., Della Penna, A., and Trull, T. W.: Autonomous profiling float observations of the high-biomass plume downstream of the Kerguelen Plateau in the Southern Ocean, Biogeosciences, 12, 2707-2735, https://doi.org/10.5194/bg-12-2707-2015, 2015.

Hassler, C. S., Ridgway, K. R., Bowie, A. R., Butler, E. C. V., Clementson, L. A., Doblin, M. A., Davies, D. M., Law, C., Ralph, P., J., van der Merwe, P., Watson, R., and Ellwood, M. J.: Primary productivity induced by iron and nitrogen in the Tasman Sea: an overview of the PINTS expedition, Mar. Freshwater Res., 65, 517-537, 2014.

Herraiz-Borreguero, L. and Rintoul, S. R.: Regional circulation and its impact on upper ocean variability south of Tasmania, Deep-Sea Res. Pt. II, 58, 2071-2081, https://doi.org/10.1016/j.dsr2.2011.05.022, 2011.

Hiscock, M. R., Lance, V. P., Apprill, A. M., Bidigare, R. R., Johnson, Z. I., Mitchell, B. G., Smith Jr., W. O., and Barber, R. T.: Photosynthetic maximum quantum yield increases are an essential component of the Southern Ocean phytoplankton response to iron, P. Natl. Acad. Sci. USA, 105, 4775-4780, 2008.

Holm-Hansen, O., Lorenzen, C. J., Holmes, R. W., and Strickland, J. D. H.: Fluorometric determination of Chlorophyll, ICES J. Mar. Sci., 30, 3-15, 1965.

Horton, P., Ruban, A. V., and Walters, R. G.: Regulation of light harvesting in green plants, Annu. Rev. Plant Physio., 47, 655684, https://doi.org/10.1146/annurev.arplant.47.1.655, 1996.

Huot, Y., Franz, B. A., and Fradette, M.: Estimating variability in the quantum yield of Sun-induced chlorophyll fluorescence: A global analysis of oceanic waters, Remote Sens. Environ., 132, 238-253, https://doi.org/10.1016/j.rse.2013.01.003, 2013.

Hutchins, D. A., Sedwick, P. N., DiTullio, G. R., Boyd, P. W., Queguiner, B., Griffiths, F. B., and Crossley, C.: Control of phytoplankton growth by iron and silicic acid availability in the subantarctic Southern Ocean: Experimental results from the SAZ project, J. Geophys. Res.-Oceans, 106, 31559-31572, 2001.

IMOS/CSIRO: IMOS-OceanCurrent-Gridded sea level anomaly Delayed mode, available at: https://portal.aodn.org.au, last access: 12 December 2018.

IMOS and Jansen, P.: IMOS-ABOS-SOTS-Pulse7-2010, available at: https://portal.aodn.org.au, last access: 12 December 2018.

Jeffrey, S. and Humphrey, G.: New spectrophotometric equations for determining chlorophyll $a, b, c 1$ and $c 2$ in higher plants, algae and natural phytoplankton, Biochem. Physiol. Pflanzen, 167, 191-194, 1975.

Kishino, M., Takahashi, M., Okami, M., and Ischimura, S.: Estimation of the spectral absorption coefficients of phytoplanktonin the seam B. Mar. Sci., 37, 634-642, 1985.

Kolber, Z. S., Barber, R. T., Coale, K. H., Fitzwater, S. E., Greene, R. M., Johnson, K. S., Lindley, S., and Falkowski, P. G.: Iron limitation of phytoplankton photosynthesis in the equatorial Pacific Ocean, Nature, 371, 145-149, 1994.

Krause, G. H. and Weis, E.: Chlorophyll fluorescence as a tool in plant physiology - II. Interpretation of fluorescence signals, Photosynth. Res., 5, 139-157, https://doi.org/10.1007/BF00028527, 1984.

Kropuenske, L. R., Mills, M. M., Van Dijken, G. L., Bailey, S., Robinson, D. H., Welschmeyer, N. A., and Arrigo, K. R.: Photophysiology in two major Southern Ocean phytoplankton taxa: Photoprotection in Phaeocystis antarctica and Fragilariopsis cylindrus, Limnol. Oceanogr., 54, 1176-1196, 2009.

Kulk, G., De Vries, P., Van De Poll, W. H., Visser, R. J. W., and Buma, A. G. J.: Temperature-dependent growth and photophysiology of prokaryotic and eukaryotic oceanic picophytoplankton, Mar. Ecol. Progr. Ser., 466, 43-55, https://doi.org/10.3354/meps09898, 2012.

Lannuzel, D., Bowie, A. R., Remenyi, T., Lam, P., Townsend, A., Ibisanmi, E., Butler, E., Wagener, T., and Schoemann, V.: Distributions of dissolved and particulate iron in the sub-Antarctic and Polar Frontal Southern Ocean (Australian sector), Deep-Sea Res. Pt. II, 58, 2094-2112, https://doi.org/10.1016/j.dsr2.2011.05.027, 2011. 
Laws, E. A.: Photosynthetic quotients, new production and net community production in the open ocean, Deep-Sea Res., 38, 143167, 1991.

Letelier, R. M., Abbott, M., and Karl, D. M.: Chlorophyll natural fluorescence response to upwelling events in the Southern Ocean, Geophys. Res. Lett., 24, 409-412, 1997.

Martínez-Gracía, A., Sigman, D. M., Ren, H., Anderson, R. F., Straub, M., Hodell, D. A., Jaccard, S. L., Eglinton, T. I., and Haug, G. H.: Iron fertilization of the subantarctic ocean during the last Ice Age, Science, 343, 1347-1350, 2014.

Mendes, C. R. B., Kerr, R., Tavano, V. M., Carvalheiro, F. A., Garcia, C. A. E., Dessai, D. R. G., and Anilkumar, N.: Cross-front phytoplankton pigments and chemotaxonomic groups in the Indian sector of the Southern Ocean, Deep-Sea Res. Pt. II, 118, 221-232, https://doi.org/10.1016/j.dsr2.2015.01.003, 2015.

Milligan, A., Aparicio, U., and Behrenfeld, M.: Fluorescence and nonphotochemical quenching responses to simulated vertical mixing in the marine diatom Thalassiosira weissflogii, Mar. Ecol. Progr. Ser., 448, 67-78, https://doi.org/10.3354/meps09544, 2012

Mitchell, B.: Algorithms for determining the absorption coefficient for aquatic particulates using the quantitative filter technique, Proc. SPIE, 1302, 137-148, 1990.

Moore, C. M., Mills, M. M., Arrigo, K. R., Berman-Frank, I., Bopp, L., Boyd, P. W., Galbraith, E. D., Geider, R. J., Guieu, C., Jaccard, S. L., Jickells, T. D., La Roche, J., Lenton, T. M., Mahowald, N. M., Maranon, E., Marinov, I., Moore, J. K., Nakatsuka, T., Oschlies, A., Saito, M. A., Thingstad, T. F., Tsuda, A., and Ulloa, O.: Processes and patterns of oceanic nutrient limitation, Nat. Geosci., 6, 1-10, https://doi.org/10.1038/ngeo1765, 2013.

Morel, A., Huot, Y., Gentili, B., Werdell, P. J., Hooker, S. B., and Franz, A. B.: Examining the consistency of products derived from various ocean color sensors in open ocean (Case 1) waters in the perspective of a multi-sensor approach, Remote Sens. Environ., 111, 69-88, 2007.

Morrison, J. R.: In situ determination of the quantum yield of phytoplankton chlorophyll a fluorescence: A simple algorithm, observations, and a model, Limnol. Oceanogr., 48, 618-631, https://doi.org/10.4319/lo.2003.48.2.0618, 2003.

Morrison, J. R. and Goodwin, D. S.: Phytoplankton photocompensation from space-based fluorescence measurements, Geophys. Res. Lett., 37, L06603, https://doi.org/10.1029/2009GL041799, 2010.

MNF: Investigator voyage IN2018_V02, available at: https://www.cmar.csiro.au/data/trawler/survey_details.cfm? survey=IN2018_V02, last access: 21 June 2018.

Müller, P., Li, X., and Niyogi, K.: Non-photochemical quenching. A response to excess light energy, Plant Physiol., 125, 1558-1566, 2001.

O’Malley, R. T., Behrenfeld, M. J., Westberry, T. K., Milligan, A. J., Shang, S., and Yan, J.: Geostationary satellite observations of dynamic phytoplankton photophysiology, Geophys. Res. Lett., 41, 5052-5059, https://doi.org/10.1002/2014GL060246, 2014.

Oxborough, K. and Baker, N. R.: Resolving chlorophyll a fluorescence images of photosynthetic efficiency into photochemical and non-photochemical components - calculation of qP and $F_{\mathrm{v}}^{\prime} / F_{\mathrm{m}}^{\prime}$ without measuring $F_{\mathrm{o}}^{\prime}$, Photosynth. Res., 54, 135-142, 1997.
Petrou, K., Trimborn, S., Rost, B., Ralph, P. J., and Hassler, C. S.: The impact of iron limitation on the physiology of the Antarctic diatom Chaetoceros simplex, Mar. Biol., 161, 925-937, https://doi.org/10.1007/s00227-014-2392-z, 2014.

Raven, J. A. and Geider, R. J.: Temperature and algal growth, New Phytol., 110, 441-461, 1988.

Rees, C., Pender, L., Sherrin, K., Schwanger, C., Hughes, P., Tibben, S., Marouchos, A., and Rayner, M.: Methods for reproducible shipboard SFA nutrient measurement using RMNS and automated data processing, Limnol. Oceanogr.-Meth., 17, 25-41, https://doi.org/10.1002/lom3.10294, 2019.

Roesler, C., Uitz, J., Claustre, H., Boss, E., Xing, X., Organelli, E., Briggs, N., Bricaud, A., Schmechtig, C., Poteau, A., D’Ortenzio, F., Ras, J., Drapeau, S., Haentjens, N., and Barbieux, M.: Recommendations for obtaining unbiased chlorophyll estimates from in situ chlorophyll fluorometers: A global analysis of WET Labs ECO sensors, Limnol. Oceanogr.-Meth., 15, 572-585, https://doi.org/10.1002/lom3.10185, 2017.

Roesler, C. S. and Barnard, A. H.: Optical proxy for phytoplankton biomass in the absence of photophysiology: Rethinking the absorption line height, Methods Oceanogr., 7, 79-94, https://doi.org/10.1016/j.mio.2013.12.003, 2013.

Rohacek, K.: Chlorophyll fluorescence parameters: The definitions, photosynthetic meaning, and mutual relationships, Photosynthetica, 40, 13-29, 2002.

Rose, J. M., Feng, Y., DiTullio, G. R., Dunbar, R. B., Hare, C. E., Lee, P. A., Lohan, M., Long, M., W. O. Smith Jr., Sohst, B., Tozzi, S., Zhang, Y., and Hutchins, D. A.: Synergistic effects of iron and temperature on Antarctic phytoplankton and microzooplankton assemblages, Biogeosciences, 6, 3131-3147, https://doi.org/10.5194/bg-6-3131-2009, 2009.

Ryan-Keogh, T. J. and Thomalla, S. J.: Deriving a proxy for iron limitation from passive chlorophyll fluorescence on buoyancy gliders, in preparation, 2020.

Ryan-Keogh, T. J., DeLizo, L. M., Smith Jr., W. O., Sedwick, P. N., McGillicuddy Jr., D. J., Moore, C. M., and Bibby, T. S.: Temporal progression of photosynthetic-strategy in phytoplankton in the Ross Sea, Antarctica, J. Mar. Sys., 166, 87-96, https://doi.org/10.1016/j.jmarsys.2016.08.014, 2017.

Schallenberg, C., Jansen, P., and Trull, T. W.: Southern Ocean Time Series (SOTS) Quality Assessment and Control Report Wetlabs FLNTUS instruments Version 2.0, CSIRO, Australia, https://doi.org/10.26198/5c4a932ca8ae4, 2019.

Schallenberg, C., Lewis, M. R., Kelley, D. E., and Cullen, J. J.: Inferred influence of nutrient availability on the relationship between Sun-induced chlorophyll fluorescence and incident irradiance in the Bering Sea, J. Geophys. Res.-Oceans, 113, C07046, https://doi.org/10.1029/2007JC004355, 2008.

Schuback, N. and Tortell, P. D.: Diurnal regulation of photosynthetic light absorption, electron transport and carbon fixation in two contrasting oceanic environments, Biogeosciences, 16, 1381-1399, https://doi.org/10.5194/bg-16-1381-2019, 2019.

Schuback, N., Schallenberg, C., Duckham, C., Maldonado, M. T., and Tortell, P. D.: Interacting effects of light and iron availability on the coupling of photosynthetic electron transport and $\mathrm{CO}_{2}$-assimilation in marine phytoplankton, PLOS ONE, 10, e0133235, https://doi.org/10.1371/journal.pone.0133235, 2015.

Sedwick, P. N., DiTullio, G. R., Hutchins, D. A., Boyd, P. W., Griffiths, F. B., Crossley, A. C., Trull, T. W., and Queginer, B.: Lim- 
itation of algal growth by iron deficiency in the Australian Subantarctic region, Geophys. Res. Lett., 26, 2865-2868, 1999.

Shadwick, E. H., Trull, T. W., Tilbrook, B., Sutton, A. J., Schulz, E., and Sabine, C. L.: Seasonality of biological and physical controls on surface ocean $\mathrm{CO}_{2}$ from hourly observations at the Southern Ocean Time Series site south of Australia, Global Biogeochem. Cy., 29, 223-238, https://doi.org/10.1002/2014GB004906, 2015.

Sigman, D. M. and Boyle, E. A.: Glacial/interglacial variations in atmospheric carbon dioxide, Nature, 407, 859-869, 2000.

Silsbe, G., Behrenfeld, M., Halsey, K., Milligan, A., and Westberry, T. K.: The CAFE model: A net production model for global ocean phytoplankton, Global Biogeochem. Cy., 30, 1756-1777, https://doi.org/10.1002/2016GB005521, 2016.

Slade, W. H., Boss, E., Dall'Olmo, G., Langner, M. R., Loftin, J., Behrenfeld, M. J., Roesler, C., and Westberry, T. K.: Underway and moored methods for improving accuracy in measurement of spectral particulate absorption and attenuation. J. Atmos. Ocean. Tech., 27, 1733-1746, https://doi.org/10.1175/2010JTECHO755.1, 2010.

Strzepek, R. F., Boyd, P. W., and Sunda, W. G.: ?Photosynthetic adaptation to low iron, light, and temperature in Southern Ocean phytoplankton, P. Natl. Acad. Sci. USA, 116, 4388-4393, 2019.

Strzepek, R. F., Hunter, K. A., Frew, R. D., Harrison, P. J., and Boyd, P. W.: Iron-light interactions differ in Southern Ocean phytoplankton, Limnol. Oceanogr., 57, 1182-1200, https://doi.org/10.4319/lo.2012.57.4.1182, 2012.

Suggett, D. J., Moore, C. M., Hickman, A. E., and Geider, R. J.: Interpretation of fast repetition rate (FRR) fluorescence: signatures of phytoplankton community structure versus physiological state, Mar. Ecol. Progr. Ser., 376, 1-19, https://doi.org/10.3354/meps07830, 2009.

Tagliabue, A., Sallée, J., Bowie, A., and Lévy, M.: Surfacewater iron supplies in the Southern Ocean sustained by deep winter mixing, Nat. Geosci., 7, 314-320, https://doi.org/10.1038/NGEO2101, 2014.
Thomalla, S. J., Moutier, W., Ryan-Keogh, T. J., Gregor, L., and Schütt, J.: An optimized method for correcting fluorescence quenching using optical backscattering on autonomous platforms, Limnol. Oceanogr.-Meth., 16, 132-144, https://doi.org/10.1002/lom3.10234, 2018.

Trees, C. C., Kennicutt, M. C., and Brooks, J. M.: Errors associated with the standard fluorimetric determination of chlorophylls and phaeopigments, Mar. Chem., 17, 1-12, https://doi.org/10.1016/0304-4203(85)90032-5, 1985.

Weeding, B. and Trull, T. W.: Hourly oxygen and total gas tension measurements at the Southern Ocean Time Series site reveal winter ventilation and spring net community production, J. Geophys. Res.-Oceans, 119, 348-358, https://doi.org/10.1002/2013JC009302, 2014.

Westwood, K. J., Griffiths, F. B., Webb, J. P., and Wright, S. W.: Primary production in the Sub-Antarctic and Polar Frontal Zones south of Tasmania, Australia; SAZ-Sense survey, 2007, DeepSea Res. Pt. II, 58, 2162-2178, 2011.

Xing, X., Briggs, N., Boss, E., and Claustre, H.: Improved correction for non-photochemical quenching of in situ chlorophyll fluorescence based on a synchronous irradiance profile, Opt. Express, 26, 24734, https://doi.org/10.1364/oe.26.024734, 2018.

Xing, X., Claustre, H., Blain, S., D’Ortenzio, F., Antoine, D., Ras, J., and Guinet, C.: Quenching correction for in vivo chlorophyll fluorescence acquired by autonomous platforms: A case study with instrumented elephant seals in the Kerguelen region (Southern Ocean), Limnol. Oceanogr.-Meth., 10, 483-495, https://doi.org/10.4319/lom.2012.10.483, 2012. 